\title{
Genetic basis for phenotypic differences between different Toxoplasma gondii type I strains
}

Ninghan Yang ${ }^{1}$, Andrew Farrell ${ }^{2}$, Wendy Niedelman ${ }^{1}$, Mariane Melo ${ }^{1}$, Diana Lu', Lindsay Julien ${ }^{1}$, Gabor T Marth², Marc-Jan Gubbels ${ }^{2}$ and Jeroen PJ Saeij ${ }^{1^{*}}$

\begin{abstract}
Background: Toxoplasma gondii has a largely clonal population in North America and Europe, with types I, II and III clonal lineages accounting for the majority of strains isolated from patients. RH, a particular type I strain, is most frequently used to characterize Toxoplasma biology. However, compared to other type I strains, RH has unique characteristics such as faster growth, increased extracellular survival rate and inability to form orally infectious cysts. Thus, to identify candidate genes that could account for these parasite phenotypic differences, we determined genetic differences and differential parasite gene expression between RH and another type I strain, GT1. Moreover, as differences in host cell modulation could affect Toxoplasma replication in the host, we determined differentially modulated host processes among the type I strains through host transcriptional profiling.

Results: Through whole genome sequencing, we identified 1,394 single nucleotide polymorphisms (SNPs) and insertions/deletions (indels) between RH and GT1. These SNPs/indels together with parasite gene expression differences between RH and GT1 were used to identify candidate genes that could account for type I phenotypic differences. A polymorphism in dense granule protein, GRA2, determined RH and GT1 differences in the evasion of the interferon gamma response. In addition, host transcriptional profiling identified that genes regulated by NF-KB, such as interleukin (IL)-12p40, were differentially modulated by the different type I strains. We subsequently showed that this difference in NF-KB activation was due to polymorphisms in GRA15. Furthermore, we observed that RH, but not other type I strains, recruited phosphorylated IKBa (a component of the NF-kB complex) to the parasitophorous vacuole membrane and this recruitment of $\mathrm{p}$ - IkBa was partially dependent on GRA2.

Conclusions: We identified candidate parasite genes that could be responsible for phenotypic variation among the type I strains through comparative genomics and transcriptomics. We also identified differentially modulated host pathways among the type I strains, and these can serve as a guideline for future studies in examining the phenotypic differences among type I strains.
\end{abstract}

Keywords: Toxoplasma, Type I strains, Comparative genomics, Transcriptomics, NF-kB

\section{Background}

Toxoplasma gondii is an obligate intracellular pathogen from the phylum Apicomplexa and is estimated to infect about one third of the world population [1]. It usually establishes an asymptomatic, chronic infection, but immunodeficient individuals can develop severe disease such as encephalitis and retinitis. Toxoplasma has a relatively complex life cycle, containing both asexual and sexual stages. The sexual cycle occurs in felines, but

\footnotetext{
*Correspondence: jsaeij@mit.edu

'Biology Department, Massachusetts Institute of Technology, 77

Massachusetts Ave, building 68-270, Cambridge, MA 02139, USA

Full list of author information is available at the end of the article
}

because a single parasite can give rise to both micro and macro-gametes, usually self fertilization occurs [2]. Sexual recombination leading to new genotypes can only occur when felines are infected simultaneously with at least two different strains [3]. The low occurrence of concurrent infection events, together with horizontal transmission between intermediate hosts through consumption of infectious cysts, likely accounts for the highly clonal population structure observed in North America and Europe [4].

In North America, three clonal lineages known as types I, II and III were thought to predominate $[5,6]$. However, recent SNP analysis at five loci in $~ 950$ strains,

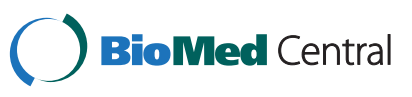


representing worldwide diversity, clustered these strains into 15 haplogroups and showed a high prevalence of type 12 strains in North America [7], while a large number of divergent strains are present in South America. Using genome-wide SNPs, it was shown that even within these haplogroups (except for haplogroups I, II, III and 6), there is often significant diversity and most strains appear to have formed through recent recombination events [8]. Between lineage diversity is estimated to be 1 to $3 \%$ while diversity within the type I, II and III clonal lineage is $\sim 0.01 \%$ [8-10]. There are also strong phenotypic differences between lineages [11], such as acute virulence in mice, with type I strains being uniformly lethal $\left(\mathrm{LD}_{100}=1\right)$, while types II and III are less virulent, with $\mathrm{LD}_{50} \geq 10^{3}$ and $\mathrm{LD}_{50} \geq 10^{5}$, respectively [11]. Another phenotype that has been correlated with virulence is in vitro growth rate, with type I parasites having a higher growth rate compared to types II and III [12].

$\mathrm{RH}$ is the most commonly used type I strain for characterization of numerous aspects of Toxoplasma biology, ranging from active invasion, replication, to host cell egress, and it has been used extensively for molecular genetic analyses. RH was initially isolated from a 1939 case of toxoplasmic encephalitis by Albert Sabin and was subsequently cloned by Elmer Pfefferkorn for in vitro culture in $1977[13,14]$. This cloned RH-ERP strain has likely undergone laboratory adaptation due to extensive in vitro lab passage, unlike RH-JSR, a non-cloned RH isolate that was propagated in mice and has undergone little serial passage in culture [15]. There are several other isolates of the type I lineage defined by PCR-RFLP at multiple marker alleles, such as GT1, an isolate from goat skeletal muscle [16], from which the complete genome has been sequenced (ToxoDB.org) [17].

Surprisingly, RH-ERP displays significant parasite phenotypic variation compared to GT1 and RH-JSR [15], with RH-ERP having increased extracellular survival times, higher in vitro growth rates and loss of ability to form orally infective cysts $[15,18]$. Moreover, using Toxoplasma microarrays, it was observed that RH-ERP parasite gene expression is significantly different compared to RH-JSR and GT1 [15], with upregulation of certain $\mathrm{ABC}$ transporters in RH-ERP compared to RHJSR or GT1. RH-ERP and GT1 also differ in the modulation of certain host processes; a serum response factor (SRF) reporter cell line is activated more by RH-ERP compared to GT1, and transcript levels of early growth response factor 2 (EGR2), a SRF target gene, are higher upon RH-ERP infection compared to GT1 $[19,20]$. In addition, there is increased immune related GTPase (IRG) coating of the parasitophorous vacuole membrane (PVM) of GT1 compared to RH-ERP in IFN- $\gamma$ stimulated mouse embryonic fibroblasts (MEFs) and subsequent higher levels of GT1 killing compared to RH-ERP
[21]. Differential modulation of host pathways could affect host cell survival or nutritional availability and subsequent Toxoplasma replication within the host cell.

The genetic basis for phenotypic variation between RH-ERP and the other type I strains is currently unknown. Many of these phenotypic differences are important determinants of acute virulence and chronic infection, as increased growth rates can lead to higher parasite burdens in vivo, and cyst formation is essential for Toxoplasma transmission [1]. Thus, understanding the genetic basis for the enhanced growth rate of RHERP and its inability to form orally infectious cysts could provide important insights into Toxoplasma virulence determinants. To examine the potential genetic basis for phenotypic differences between RH-ERP and GT1, we compared the complete genome sequences of RH-ERP and GT1 and identified single nucleotide polymorphisms (SNPs) and insertions/deletions (indels) across the genome. We also compared differential parasite gene expression between RH-ERP and RH-JSR/GT1 through our own independent transcriptional profiling and previous studies [15,22]. Using our SNP/indel and differentially expressed gene list, we then identified a number of candidate genes that could be responsible for the phenotypic differences observed between RH-ERP and RH-JSR/GT1, including a dense granule protein, GRA2. We then attributed the differences between RH-ERP and GT1 in evasion of IFN- $\gamma$-mediated killing in MEFs to GRA2. To identify novel differences in host cell modulation among type I strains, we performed transcriptional profiling of human foreskin fibroblasts (HFFs) infected with RH-ERP, RH-JSR and GT1. Several host pathways were found to be differentially modulated, such as the NF- $\mathrm{kB}$ pathway, which is activated by GT1 but not by RH-ERP or RH-JSR. Other host phenotypes that were different across type I strains included IL-12p40 (a NF- $\kappa B$ dependent cytokine) secretion by infected macrophages and recruitment of p-IкB $\alpha$ to the PVM, which was partially dependent on GRA2. Our results show that genetic mutations accumulated over time due to continuous laboratory passaging, can lead to large phenotypic changes and the candidate genes identified can serve as a guideline for future studies in examining phenotypic differences among type I strains.

\section{Methods}

\section{Parasites and cells}

Human foreskin fibroblasts (HFFs) were grown in DMEM (Invitrogen) supplemented with 10\% heat inactivated FBS (PAA), $50 \mu \mathrm{g} / \mathrm{ml}$ each of penicillin and streptomycin, and $20 \mu \mathrm{g} / \mathrm{ml}$ gentamycin. A HEK293T stable reporter cell line with four copies of the NF-kB consensus transcriptional response element driving the expression of GFP and luciferase (System Biosciences) were grown in the same DMEM but supplemented with $1 \mathrm{mM}$ sodium pyruvate, 
$100 \mu \mathrm{M}$ MEM nonessential amino acids and $10 \mathrm{mM}$ HEPES. These NF-kB 293T reporter cells were passed every 2-4 days using 0.05\% trypsin-EDTA [23]. C57BL/6J mouse embryonic fibroblasts (MEFs) were a gift from A. Sinai (University of Kentucky College of Medicine, Lexington, KY) and grown in HFF media supplemented with $10 \mathrm{mM}$ HEPES. Parasites were maintained in vitro by serial passage on monolayers of $\mathrm{HFFs}$ at $37^{\circ} \mathrm{C}$ in $5 \% \mathrm{CO}_{2}$. $\mathrm{RH}$-ERP is a clone of the original $\mathrm{RH}$ isolate, subjected to continuous passage in vitro until the time of present study. RH-JSR was a gift from David Sibley (Washington University in St. Louis, Saint Louis, MO) and is a noncloned line of the original $\mathrm{RH}$ isolate, subjected to propagation in mice and cryopreserved since 1988. GT1 was originally isolated from skeletal muscle of a goat in 1980, and was subject to passage in laboratory conditions [15].

\section{Reagents}

All tissue culture reagents were purchased from Gibco (Life Technologies Corporation, USA), unless otherwise stated. Antibodies against Toxoplasma dense granule protein GRA7 were kindly provided by John Boothroyd (Stanford University, Palo Alto, CA) [24]. Anti-mouse p-IkB $\alpha$ (sc-8404), anti-human NF-kB p65 (sc-109) and anti-mouse TGTP (sc-11079) antibodies were purchased from Santa Cruz Biotechnology (California, USA). Recombinant human TNF $\alpha$ was obtained from Invitrogen (Life Technologies Corporation, USA), and lipopolysaccharide was purchased from EMD Millipore (Merck KGaA, Darmstadt, Germany).

\section{Generation of transgenic parasites}

To generate RH-ERP ( $\triangle \mathrm{HXGPRT}$ ) parasites expressing the GT1 allele of GRA15, the GRA15 coding region and putative promoter $(1,940 \mathrm{bp}$ upstream of the start codon) was amplified from GT1 genomic DNA by PCR (forward, 5'-CACCTTGACTGCCACGTGTAGTATCC-3', reverse, 5' -TTACGCGTAGTCCGGGACGTCGTACGGGT ATGGAGTTACCGCTGATTGTGT-3'). Sequence coding for a $\mathrm{C}$ terminal $\mathrm{HA}$ tag was included in the reverse primer (denoted with italics). GRA $15_{\mathrm{GT} 1} \mathrm{HA}$ was then cloned into pENTRD/D-TOPO (Invitrogen), and into pTKO-att [23] through LR recombination (Invitrogen). The pTKO-att-GRA15 ${ }_{\mathrm{GT} 1} \mathrm{HA}$ vector was then linearized by digestion with XhoI (New England Biolabs, Inc.). Linearized vector was transfected into RH-ERP $\triangle H X G P R T$ by electroporation as previously described [23]. Stable integrants were selected in media with $50 \mu \mathrm{g} / \mathrm{ml}$ mycophenolic acid (Axxora) and $50 \mu \mathrm{g} / \mathrm{ml}$ xanthine (Alfa Aesar) and cloned by limiting dilution. Immunofluorescence was used to confirm expression of GRA $15_{\mathrm{GT} 1}$ via HA staining.

To generate RHAgra2 parasites complemented with either RH-ERP GRA2 or GT1 GRA2, the GRA2 coding region and putative promoter $(1,143 \mathrm{bp}$ upstream of the start codon) was amplified from RH-ERP ( $\triangle$ HXGPRT) and GT1 genomic DNA by PCR (forward, 5' -GGGG ACAACTTTTCTATACAAAGTTGAGCATGTAGGT GGAACGC-3', reverse, 5'-TTACGCGTAGTCCGGGACGT CGTACGGGTACTGCGAAAAGTCTGGGAC-3'). Sequence coding for the attP4r recombination site was included in the forward primer and a $\mathrm{C}$ terminal $\mathrm{HA}$ tag was included in the reverse primer (attP4r in bold and HA tag in italics). A second PCR added the attP3 recombination site after the HA tag and the insert was cloned into pDONR 221 P4r-P3r (Invitrogen) using BP recombination (Invitrogen). The GRA2-HA insert was then flanked by the genomic DNA both upstream and downstream of the UPRT locus and inserted into the pTKO2 destination vector [23] by LR recombination (Invitrogen). pTKO2-GRA2HA was linearized by digestion with HindIII (New England Biolabs, Inc.) which does not cut within GRA2 and pTUB-CAT was digested with NotI (New England Biolabs, Inc.). pTKO2-GRA2HA and pTUB-CAT were co-transfected into RHAgra2 as previously described [23]. Stable integrants were selected by passage of $10^{6}$ parasites every 2 days in $2 \mu \mathrm{M}$ chloramphenicol and cloned by limiting dilution. Immunofluorescence and Western blot were used to confirm expression of RH-ERP GRA2 or GT1 GRA2 via HA staining.

\section{Luciferase assays}

HEK293T NF-kB reporter cells were seeded at a density of $4 \times 10^{4}$ cells per well for 4 hours in a black 96 well clear bottom plate (Corning). Parasites were syringed lysed, washed once with PBS and three different multiplicity of infection (MOIs) per strain were used to infect reporter cells. As a positive control, recombinant human TNF $\alpha$ was used at $20 \mathrm{ng} / \mu \mathrm{l}$ to stimulate uninfected cells at the same time as infection. After 24 hours of infection, uninfected, stimulated and infected cells were lysed using Cell Culture Lysis reagent, and luciferase activity in lysates was measured according to manufacturer's protocol (Promega). Data from cells infected with similar MOIs, as determined by plaque assay, were used.

\section{In vitro cytokine ELISAs}

C57BL/6 bone marrow-derived macrophages (BMMs) were isolated as described [25], and plated in DMEM, supplemented with 20\% L929 supernatants, two days before infection. Parasites were syringe lysed, washed once with PBS and three different MOIs per strain were used to infect uninfected macrophages. As a positive control, purified lipopolysaccharide $(100 \mathrm{ng} / \mathrm{mL})$ was used to stimulate uninfected BMMs 3 hours before supernatants were collected. After 24 hours of infection, supernatants from uninfected, stimulated and infected cells were collected and stored at $-80^{\circ} \mathrm{C}$ until ELISAs were performed. 
IL-12/23p40 and CCL2/MCP-1 levels in culture supernatants were determined using commercially available ELISA kits (ELISA DuoSet ${ }^{\oplus}, \mathrm{R} \& D$ Biosystems), according to the manufacturer's instructions.

\section{Immunofluorescence}

Irgb6 staining in MEFs were performed as previously described [21]. Percent Irgb6 coating was determined in a blind fashion by finding intracellular parasites and then scoring Irgb6 coating as positive or negative. For p65 and $\mathrm{p}-\mathrm{I} \kappa \mathrm{B} \alpha$ staining, HFFs were plated on coverslips in 24 well plates until confluent, and subsequently infected with parasites for different timepoints. HFFs were then fixed with 3\% ( $\mathrm{vol} / \mathrm{vol}$ ) formaldehyde in PBS for $20 \mathrm{~min}$ at room temperature, permeabilized with $0.2 \%$ ( $\mathrm{vol} / \mathrm{vol})$ Triton X-100 in PBS, and blocked in PBS with 3\% (wt/vol) BSA and $5 \%$ (vol/vol) goat serum. Coverslips were incubated with primary antibodies overnight at $4{ }^{\circ} \mathrm{C}$, and fluorescent secondary antibodies, coupled with Alexa Fluor 488 or 594 (Invitrogen), and Hoechst dye were used for antigen and DNA visualization, respectively. Coverslips were mounted on a glass slide with Vectashield (Vector laboratories) and photographs were taken using NIS-Elements software (Nikon) and a digital camera (CoolSNAP EZ, Roper industries) connected to an inverted fluorescence microscope (model eclipse Ti-S, Nikon).

Quantification of p65 nuclear localization was performed as previously described [23]. Quantification of $\mathrm{p}-\mathrm{I} \kappa \mathrm{B} \alpha$ localized to the PVM was performed using NIS-Elements software (Nikon). Parasitophorous vacuoles (PVs) were chosen at random through GRA7 staining. The intensity of fluorescent $\mathrm{p}$ - IкB $\alpha$ was measured by drawing two lines at right angles across the long and short axes of the vacuoles, and intensity profiles were obtained for each line. The fold change intensity of each line was taken by dividing the highest peak value where each line crossed the margins of the PVM by the lowest value for each line (taken as background). The signal intensity for each vacuole was given as the mean of the two intensity fold changes obtained per vacuole.

\section{Plaque assays}

Plaque assays were set up as previously described [21]. Briefly, MEFs were seeded the day before, and stimulated with $1000 \mathrm{U} / \mathrm{ml}$ mouse IFNy or left unstimulated before infection in a 24 well plate. Plaques were then counted in unstimulated and stimulated MEFs after incubation for 4-7 days at $37^{\circ} \mathrm{C}$.

\section{SNP and INDEL list generation between RH-ERP and GT1}

To reduce the posibility of sequence errors and cell line specific mutations, genomic DNA from two related RH-ERP lines, 2F-1-YFP2 parent and an F-P2 ENU mutagenized child, were prepared and sequenced [26]. Illumina sequencing produced 40,495,290 and 43,514,016 reads for the parent and F-P2 samples respectively. The FASTQ sequence traces were aligned to a FASTA reference containing both Toxoplasma gondii GT1 genomic reference v5.0 and the Human genome reference build 37. Reads were aligned to the GT1 genome as well as the Human genome to filter out any possible human contamination. MOSAIK v1.0 was used to perform the alignments using the standard parameters. Greater than $90 \%$ of the reads aligned for each sample, with rougly half of the reads filtered out as human contamination. Variants were called using the variant caller FreeBayes [27] using standard parameters, software version 0.7.2. Varations were then filtered to identify variants that were called in both parental and F-P2 samples at an allele balance greater than $75 \%$.

\section{RH-ERP and GT1 gene expression via RNA-seq}

RNA was isolated from C57BL/6 bone marrow derived macrophages infected with RH-ERP and GT1. These were processed and sequenced as described previously [8]. Reads were then mapped to the GT1 genome (ToxoDB.org).

\section{Toxoplasma microarray analysis}

For Toxoplasma arrays, image analysis files (.CEL) files from published microarray data from HFFs infected with RH-ERP, RH-JSR or GT1 were downloaded from the Gene Expression Omnibus (GEO) database (Series GSE16115 and GSE22315). In addition, independent Toxoplasma arrays were performed on total RNA isolated from HFFs infected for 24 hours with RH-ERP, RH-JSR and GT1 (Series GSE44191). Each sample was hybridized to the T. gondii Affymetrix microarray [22]. The image analysis files from GSE16115, GSE22315 and GSE44191 were all processed together using the Expression Console Software, normalized using Robust Multi Array (RMA) algorithm, and all background values less than 6.5 were set to 6.5. These arrays were then imported into Multi-Experiment Viewer (MeV) [28], all genes were median-centered and loaded into Genomica [29] as the array dataset.

To create Genomica and GSEA custom gene sets to determine biological function enrichment [29,30], we downloaded the Gene Ontology (GO) and InterPro (IP) annotations for Toxoplasma genes using the ME49 v8 reference genome (ToxoDB.org). To determine functional enrichment in groups of genes with similar annotations (gene sets), gene sets were loaded into Genomica [29] and selected as gene sets to analyze. The default parameters were used to run the hypergeometric enrichment analysis (the complete set of Toxoplasma gene IDs and their associated functional assignments in Genomica or GSEA format is available from the authors upon request). 


\section{Human microarray analysis}

HFFs were grown in 6 well plates until confluency was reached. Parasites were syringe lysed and washed once with PBS. HFFs were infected with RH-ERP, RH-JSR and GT1 at three different MOIs for 24 hours. Plaque assays were done to assess viability of parasites and infections with similar MOIs were chosen. Three biological replicates were done for RH-ERP and RH-JSR while two biological replicates were done for GT1. TRIzol reagent (Invitrogen) was used to isolate total RNA according to the manufacturer's instructions and RNA was cleaned up using MiniElute kit (Qiagen). RNA was labeled and hybridized to human Affymetrix arrays (Human U133A 2.0) according to manufacturer's protocol. Probe intensities were measured with the Affymetrix GeneChip Scanner $30007 \mathrm{G}$ and were processed into image analysis (.CEL) files with Expression Console Software (Affymetrix), which can be accessed through GEO (GSE44189). Intensity values were normalized using RMA through Expression Console, and all background values less than 6.5 were set to 6.5 .

GSEA was used to find candidate transcription factors and canonical pathways that were modulated differently between the type I Toxoplasma strains [30]. Both transcription factor and canonical pathway gene sets from the Molecular Signatures Database (MSigDB) were used to determine enrichment (c2.cp. symbols, c3.tft. symbols), using default parameters except the range of set size, which was changed to a minimum of 5 and maximum of 3000. Analysis of distant regulatory elements of coregulated genes (DiRE, http://dire.dcode.org) [31] was performed using a random set of 5000 background genes and using target elements of top 3 evolutionary conserved regions (ECRs) and promoter ECRs. For every gene in a list, DiRE detects regulatory elements throughout the entire gene locus and looks for enrichment of transcription factor binding sites.

\section{Results and discussion}

Identification of genetic differences between RH-ERP and GT1

To determine the genetic differences between RH-ERP and GT1, we sequenced RH-ERP using Illumina sequencing and downloaded the complete genome sequence of GT1 (Table 1A and ToxoDB.org). A list of single nucleotide polymorphisms (SNPs) and insertions/deletions (indels) between RH-ERP and GT1 was generated, and a total number of 1,394 SNPs and indels were identified. There were 230 SNPs/indels within predicted coding regions, 484 SNPs/indels within predicted genes but outside coding regions, and $680 \mathrm{SNPs} /$ indels outside predicted genes. From the $230 \mathrm{SNP} /$ indels within predicted coding regions, we further identified 133 SNPs leading to nonsynonymous amino acid changes, 43 SNPs leading to synonymous amino acid substitutions, and 54 indels within predicted coding regions (Table $1 \mathrm{~B}$ and Additional file 1: Table S1).

We then determined whether there was functional enrichment in the genes containing the 1,394 SNPs/indels. Genes with nonsynonymous SNPs and indels within coding regions were enriched in $3^{\prime} 5^{\prime}$ cyclic nucleotide phosphodiesterase, protein kinase, ATP binding and metal ion binding activities ( $p$-value $<0.05)$. Genes with SNP/indels within 1000 bp upstream of predicted ATG start were enriched in nucleoside triphosphatase, nucleotide binding and ATPase activities ( $p$-value < 0.05) (Table 1C). Interestingly, addition of a cGMP-specific phosphodiesterase inhibitor, Zaprinast, has been shown to induce Toxoplasma egress from host cells [32]. Moreover, deletion of phosphodiesterase $\delta$ in a related Apicomplexan, Plasmodium berghei, caused severe defects in formation of normal ookinetes and ookinete gliding motility [33]. Thus, it is possible that the phosphodiesterases that have nonsynonymous SNPs and/or indels could contribute to differences in growth rate of RH-ERP compared to GT1.

RH-ERP tachyzoites grow faster, have higher extracellular viability and loss in ability to form orally infectious cysts compared to GT1/RH-JSR tachyzoites $[15,18]$. Thus, these phenotypic differences are likely due to parasite genes that are polymorphic and/or differentially expressed between RH-ERP and GT1. We used our SNP/indel data and Toxoplasma gene expression data to identify candidate genes, focusing on genes that have non-synonymous, non-conservative SNPs and/or are differentially expressed between RH-ERP and RH-JSR/GT1.

\section{Analysis of genes with polymorphisms in coding regions between RH-ERP and GT1}

From the list of 133 nonsynonymous SNPs, we identified 104 SNPs which led to non-conservative amino acid changes. We then identified 33 SNPs in genes which had transcript levels expressed above background levels of 6.5 in RH-ERP tachyzoites through Toxoplasma array data $[15,22]$, and identified several candidate genes which could lead to differences in phenotypes between RH-ERP and GT1 (Table 2A and Additional file 1: Table $\mathrm{S} 1)$. The gene encoding for dense granule protein GRA2 (TGGT1_083030) was found to have a glycine (GT1) to serine (RH-ERP) substitution, and was expressed highly in both RH-ERP and GT1 from array data. RHAgra2 differs in several phenotypes compared to parental $\mathrm{RH}$ ERP ( $\triangle$ HXGPRT), such as the disruption of the intravacuolar network within the PV, decreased virulence in mice and enhanced susceptibility to IRG-mediated killing $[21,34,35]$.

Interestingly, an ATP-dependent RNA helicase (TGGT1_081400) contained one conservative and two 
Table 1 Genetic differences between RH-ERP and GT1

\begin{tabular}{|c|c|c|c|c|c|c|}
\hline \multicolumn{7}{|c|}{ A. Summary of comparative genome sequencing between RH-ERP and GT1 } \\
\hline \multicolumn{3}{|l|}{ Description } & \multicolumn{2}{|l|}{ RH-ERP (parental) } & \multicolumn{2}{|c|}{ RH-ERP F-P2 (mutant) } \\
\hline \multicolumn{3}{|c|}{ Total base pairs sequenced } & \multicolumn{2}{|l|}{$6.1 \times 10^{9}$} & \multicolumn{2}{|l|}{$6.5 \times 10^{9}$} \\
\hline \multicolumn{3}{|c|}{ Total paired end reads } & \multicolumn{2}{|l|}{$4.0 \times 10^{7}$} & \multicolumn{2}{|l|}{$4.4 \times 10^{7}$} \\
\hline \multicolumn{3}{|l|}{ Total reads aligned } & \multicolumn{2}{|l|}{$3.7 \times 10^{7}$} & \multicolumn{2}{|l|}{$3.9 \times 10^{7}$} \\
\hline \multicolumn{3}{|c|}{ Total reads aligned (\%) } & \multicolumn{2}{|l|}{90.1} & \multicolumn{2}{|l|}{90.5} \\
\hline \multicolumn{3}{|l|}{ Human reads (\%) } & \multicolumn{2}{|l|}{32.2} & \multicolumn{2}{|l|}{49.4} \\
\hline \multicolumn{3}{|c|}{ Toxoplasma gondii reads (\%) } & \multicolumn{2}{|l|}{57.9} & \multicolumn{2}{|l|}{44.1} \\
\hline \multicolumn{3}{|c|}{ GT1 genome covered (\%) } & \multicolumn{2}{|l|}{96.5} & \multicolumn{2}{|l|}{96.9} \\
\hline \multicolumn{3}{|c|}{ Reads in unassembled contigs (\%) } & \multicolumn{2}{|l|}{0.9} & \multicolumn{2}{|l|}{0.7} \\
\hline \multicolumn{3}{|c|}{ Total Shared Variation Called } & \multicolumn{4}{|l|}{1,394} \\
\hline \multicolumn{7}{|c|}{ B. Genetic differences between RH-ERP and GT1 } \\
\hline \multirow{3}{*}{\multicolumn{2}{|c|}{$\begin{array}{l}\text { SNPs/indels within predicted } \\
\text { coding regions }\end{array}$}} & 230 & \multicolumn{2}{|l|}{ Nonsynonymous SNPs } & 133 & \\
\hline & & & Synonymous SNPs & & 43 & \\
\hline & & & Indels & & 54 & \\
\hline $\begin{array}{l}\text { SNPs/indels within } p \\
\text { genes, outside codin }\end{array}$ & $\begin{array}{l}\text { redicted } \\
\text { hg regions }\end{array}$ & 484 & $\begin{array}{l}\text { SNPs/indels in } 1000 \mathrm{bp} \\
\text { of predicted ATG start (5 }\end{array}$ & $\begin{array}{l}\text { upstream } \\
5^{\prime} \text { UTR) }\end{array}$ & $\begin{array}{l}\text { SNPs/indels in } 10 \\
\text { of predicted end }\end{array}$ & $\begin{array}{l}\text { O bp downstream } \\
\text { codon (3'UTR) }\end{array}$ \\
\hline SNPs/indels outside & predicted genes & 680 & 133 & & 143 & \\
\hline C. Functional enricl & hment in genetic diff & ces betw & RH-ERP and GT1 & & & \\
\hline Gene set & $\begin{array}{l}\text { Enrichment in Gene } \\
\text { Ontology function }\end{array}$ & P-value & $\begin{array}{l}\text { Number of annotated } \\
\text { genes with SNPs/indels }\end{array}$ & $\begin{array}{l}\text { Percent of annotated } \\
\text { genes with SNPs/indels } \\
\text { in gene set (\%) }\end{array}$ & $\begin{array}{l}\text { Total number of } \\
\text { genes annotated }\end{array}$ & $\begin{array}{l}\text { Percent of } \\
\text { annotated genes } \\
\text { in genome (\%) }\end{array}$ \\
\hline $\begin{array}{l}\text { Nonsynonymous } \\
\text { SNPs and indels }\end{array}$ & $\begin{array}{l}3^{\prime} 5^{\prime} \text {-cyclic nucleotide } \\
\text { phosphodiesterase }\end{array}$ & $3.57^{-03}$ & 3 & 2.19 & 16 & 0.24 \\
\hline $\begin{array}{l}\text { within predicted } \\
\text { gene coding }\end{array}$ & Protein kinase & $9.74^{-03}$ & 7 & 5.11 & 120 & 1.75 \\
\hline regions & ATP binding & 0.02 & 11 & 8.03 & 270 & 3.93 \\
\hline $\begin{array}{l}\text { SNPs/indels within } \\
5^{\prime} \text { UTR of predicted }\end{array}$ & $\begin{array}{l}\text { Nucleoside } \\
\text { triphosphatase }\end{array}$ & $8.47^{-03}$ & 4 & 4.17 & 58 & 0.85 \\
\hline $\begin{array}{l}\text { genes (1000 bp } \\
\text { upstream of }\end{array}$ & Nucleotide binding & 0.01 & 5 & 5.21 & 103 & 1.50 \\
\hline ATG start) & ATPase activity & 0.03 & 3 & 3.13 & 48 & 0.70 \\
\hline
\end{tabular}

(A) Details for genome sequencing of RH-ERP parental and RH-ERP F-P2 mutant, where common variants between these two strains were determined as SNPs/ indels between RH-ERP and GT1. (B) Total number of single nucleotide polymorphisms (SNPs) and insertions/deletions (indels) identified between RH-ERP and GT1, with the number of SNPs/indels identified in each category as indicated. (C) Top three functional enrichment of nonsynonymous SNPs and indels present in gene coding regions, together with genes which contain SNP/indels 1000 bp upstream of predicted ATG start, using hypergeometric enrichment.

non-conservative nonsynonymous SNPs, indicating possible positive selection in this gene and was highly expressed in RH-ERP and GT1 from array and RNAseq data (Additional file 1: Table S1). RNA helicases of the DEAD box family are involved in multiple aspects of RNA metabolism, ranging from formation of the exon junction complex, mRNA export and translation initiation [36]. Interestingly, eIF4A, the model of DEAD helicases, has been shown to be downregulated at the transcript level in attenuated type I tachyzoites (through prolonged in vitro passage) and type II bradyzoites compared to virulent type I tachyzoites [37].

In addition, SRS29A and SRS29C both had a nonconservative, nonsynonymous amino acid substitution, and were highly expressed in both RH-ERP and GT1 in array data. SRS29A was also 1.7 fold more highly expressed in RH-ERP extracellular tachyzoites compared to RH-ERP intracellular tachyzoites (Additional file 1: Table S1). A recent study showed that RH-ERP overexpressing SRS29C was significantly attenuated in mouse virulence compared to parental RH-ERP strain, though this overexpressing strain did not have any significant differences from the parental strain with regards to invasion, attachment or growth in vitro [38].

Another candidate gene identified was GAP50 (TGGT1_030300), with a isoleucine (GT1) to asparagine (RH-ERP) substitution and was highly expressed in both RH-ERP and GT1 in array data (Table 2A). GAP50 is the membrane anchor of the glideosome complex, which is required for gliding motility [39]. It also interacts with other components such as TgMyoA, TgMLC1 and TgGAP45, and requires $\mathrm{N}$-glycosylation for proper localization to the 
Table 2 Top candidate genes that have nonsynonymous amino acid changes between RH-ERP and GT1

\begin{tabular}{lllll}
\hline A. Candidate genes containing nonsynonymous SNPs between RH-ERP and GT1 & & \\
\hline ToxoDB GT1 ID & ToxoDB annotation & $\begin{array}{l}\text { A.A. change } \\
\text { (GT1 to RH-ERP) }\end{array}$ & $\begin{array}{l}\text { RH-ERP expression } \\
\text { (Microarray) }\end{array}$ & $\begin{array}{c}\text { Possible involvement in } \\
\text { Toxoplasma process }\end{array}$ \\
TGGT1_083030 & 28 kDa antigen, putative (GRA2) & Gly to Ser & 13.8 & Growth \\
TGGT1_113990 & SRS29C & Ser to Phe & 13.5 & Invasion \\
TGGT1_114020 & SRS29A & Val to Met & 12.7 & Invasion \\
TGGT1_069190 & DEAD/DEAH box helicase, putative & lle to Asn & 11.9 & Transcriptional control \\
TGGT1_030300 & acid phosphatase, putative (GAP50) & lle to Asn & 11.4 & Gliding motility \\
TGGT1_020630 & conserved hypothetical protein & Leu to Arg & 11.1 & Growth \\
& (contains glycosyltransferase 17 family) & & Translation \\
TGGT1_066370 & hypothetical protein (eukaryotic initiation factor 3) & Leu to Phe & 10.7 & Transcriptional control \\
TGGT1_081400 & ATP-dependent RNA helicase, putative & Arg to Cys & 9.6 & Ala to Asp \\
TGGT1_069890 & apoptosis-regulating basic protein, putative & Leu to Phe & 8.8 & Growth \\
TGGT1_118630 & U2 small nuclear ribonucleoprotein, putative & Thr to lle & 8.7 & Growth \\
TGGT1_098160 & Coronin, putative & Met to Val & 8.6 & Gliding motility \\
TGGT1_086050 & sushi domain-containing protein (RON1) & Asp to Gly & 7.9 & Invasion \\
TGGT1_009970 & CCR4-NOT transcription complex subunit, putative & Pro to Ser & 7.6 & Transcriptional control
\end{tabular}

B. Candidate extracellular viability genes containing nonsynonymous SNPs between RH-ERP and GT1

\begin{tabular}{llll}
\hline ToxoDB GT1 ID & ToxoDB annotation & $\begin{array}{l}\text { A.A. change } \\
\text { (GT1 to RH-ERP) }\end{array}$ & $\begin{array}{l}\text { Fold change between extracellular } \\
\text { and intracellular tachyzoites }\end{array}$ \\
TGGT1_057870 & $\begin{array}{l}\text { conserved hypothetical protein } \\
\text { (contains RNA recognition motif) }\end{array}$ & 2.6 \\
TGGT1_021310 & $\begin{array}{l}\text { pinA, putative (contains forkhead associated domain) } \\
\text { TGGT1_104520 }\end{array}$ & $\begin{array}{l}\text { Phe to Leu } \\
\text { conserved hypothetical protein }\end{array}$ & 2.0 \\
TGGT1_016250 & $\begin{array}{l}\text { hypothetical protein (cyclic nucleotide-binding } \\
\text { domain-containing protein) }\end{array}$ & lle to Asn & 2.0 \\
TGGT1_065470 & $\begin{array}{l}\text { conserved hypothetical protein } \\
\text { (contains oligomerization domain) }\end{array}$ & Ser to Cys & -2.3 \\
TGGT1_098520 & $\begin{array}{l}\text { EF hand domain-containing protein, putative } \\
\text { apyrase, putative }\end{array}$ & Val to Phe & -2.6 \\
TGGT1_087130 & acylamino-acid-releasing enzyme, putative & Pro to Leu & -3.2 \\
TGGT1_026200 & Trp toP & -3.5
\end{tabular}

\section{Candidate bradyzoite genes containing nonsynonymous SNPs between RH-ERP and GT1}

\begin{tabular}{|c|c|c|c|c|}
\hline ToxoDB GT1 ID & ToxoDB annotation & $\begin{array}{l}\text { A.A. change } \\
\text { (GT1 to } R H \text {-ERP) }\end{array}$ & $\begin{array}{l}\text { Fold change between } 8 \text { day } \\
\text { M4 in vitro bradyzoites and } \\
2 \text { day M4 tachyzoites }\end{array}$ & $\begin{array}{l}\text { Fold change between } \\
21 \text { day M4 in vivo cysts } \\
\text { and } 2 \text { day M4 tachyzoites }\end{array}$ \\
\hline TGGT1_013440 & conserved hypothetical protein & Gly to Ser & 1.8 & 1.6 \\
\hline TGGT1_020630 & $\begin{array}{l}\text { conserved hypothetical protein } \\
\text { (contains glycosyltransferase } 17 \text { family) }\end{array}$ & Leu to Arg & 2.3 & 1.5 \\
\hline
\end{tabular}

(A) Candidate genes that have non-conservative, nonsynonymous amino acid changes between RH-ERP and GT1 and are expressed highly in RH-ERP as determined by Toxoplasma arrays. Toxoplasma array expression values are log2 transformed values, ranging from 6.5 (minimum) to 14.3 (maximum). (B) Candidate genes that are differentially expressed between intracellular and extracellular RH-ERP tachyzoites [44]. (C) Candidate genes that are differentially expressed between M4 in vitro tachyzoites, in vitro induced bradyzoites and in vivo cysts [46].

inner membrane complex [40,41]. Interestingly, a rhoptry neck protein, RON1 (TGGT1_086050), has an aspartic acid (GT1) to glycine (RH-ERP) substitution, and is 1.3 fold more highly expressed in RH-ERP compared to GT1 in RNAseq data (Additional file 1: Table S1). RON1 has a distinct rhoptry neck localization [42], and several rhoptry neck proteins constitute the moving junction, which is required for invasion of the host cell [43]. Thus, polymorphisms in these genes could account for differences in invasion, growth or extracellular viability between RH-ERP and GT1.

We also examined these 104 non-conserved, nonsynonymous SNPs for genes that are differentially expressed between RH-ERP intracellular and extracellular 
tachyzoites [44], as RH-ERP has increased extracellular viability compared to GT1 [15]. We noted a predicted acylamino-acid releasing enzyme (TGGT1_026200) that contained a nonsense mutation leading to a premature stop codon, and had decreased expression in extracellular tachyzoites (Table 2B). In addition, a putative pinA gene (TGGT1_021310) with a phenylalanine (GT1) to leucine (RH-ERP) substitution had increased 2.0 fold expression in extracellular tachyzoites compared to intracellular tachyzoites. This parasite gene contains a forkhead associated domain that is involved in binding to phosphopeptides and forkhead-type transcription factors are involved in the regulation of cell cycle stage specific transcription in budding yeast [45]. Thus, these genes could be involved in the difference in extracellular viability reported between RH-ERP and GT1.

RH-ERP also exhibits a loss in ability to form orally infective cysts, unlike GT1 [18]. Thus, we also examined the 104 non-conserved, nonsynonymous SNPs for parasite genes which are differentially expressed between M4 (type II) tachyzoites, M4 in vitro bradyzoites and M4 in vivo cysts [46]. Two parasite genes containing substitution polymorphisms between RH-ERP and GT1 were upregulated in both in vitro bradyzoites and in vivo cysts (Table 2C). One of the genes (TGGT1_020630) contains a glycosyltransferase domain that is involved in transferring $\mathrm{N}$-acetylglucosamine to the core mannose of complex N-glycans. Interestingly, TGGT1_020630 was also identified to be consistently more highly expressed in RH-ERP compared to GT1 (Table 3B). Thus, this gene could potentially be involved in the loss of ability in RH-ERP to form orally infectious cysts, as bradyzoites contain numerous amylopectin granules and the tissue cyst wall consists of lectin binding sugars [47,48].

\section{RH-ERP and GT1 GRA2 both complement Irgb6 coating but show differences in IRG mediated killing}

As mentioned above, GRA2 was found to have a single polymorphism from glycine (GT1) to serine (RH-ERP) in our SNP analysis. Furthermore, previous work on Toxoplasma immune evasion mechanisms have shown that RH-ERP infected IFN- $\gamma$ stimulated MEFs had decreased percentage of parasite vacuoles coated with Irgb6, an immunity related GTPase (IRG), compared to GT1 infected MEFs [21]. In addition, RH $\Delta$ gra2 infected IFN- $\gamma$ stimulated MEFs had increased percentage of parasite vacuoles coated with Irgb6 compared to $\mathrm{RH}$ ERP infected MEFs. Thus, we examined the possible effects of the GRA2 polymorphism on Irgb6 coating and IRG evasion through complementation of RH $\triangle$ gra 2 with either RH-ERP GRA2 or GT1 GRA2.

As noted previously, there was a significant difference between RH-ERP and RHAgra2 or GT1 in percentage of parasite vacuoles coated with Irgb6 (Figure $1 \mathrm{~A}$ and $1 \mathrm{~B}$, $p$-value $=0.0004(\mathrm{RH} \Delta$ gra 2$)$ and $p$-value $=0.002(\mathrm{GT} 1)$,
Student's $t$ test). Both RH-ERP GRA2 and GT1 GRA2 were able to complement Irgb6 coating, as both complemented strains had similar percentage parasite vacuoles coated with Irgb6 compared to RH-ERP. However, some Toxoplasma parasites are still able to survive, escape IRG coated vacuoles and invade a new cell, thus Irgb6 coating may not fully measure parasite killing [49]. Therefore, to measure IFN- $\gamma$ mediated killing in MEFs, the relative number of parasite plaques that form 4-7 days on IFN- $\gamma$ stimulated MEFs compared to unstimulated MEFs were measured (also referred to as plaque loss). Surprisingly, unlike Irgb6 coating, there were differences between the two complemented strains in the plaque loss assay (Figure 1B), though both complemented strains expressed similar levels of GRA2 (Additional file 2: Figure S1). The RH-ERP GRA2 was able to complement the difference in plaque loss between RH-ERP and RH $\Delta g r a 2$, with no significant difference in plaque loss between RH-ERP and RH $\Delta$ gra $2+$ RH-ERP-GRA2 $(p$-value $=0.33$, Student's $t$ test $)$. However, the GT1 GRA2 was unable to complement the difference in plaque loss, and there was still a significant difference in plaque loss between RH-ERP and RHAgra2+GT1GRA2 ( $p$-value $=0.008$, Student's $t$ test), similar to the difference observed between RH-ERP and GT1 ( $p$-value = 0.01 , Student's $t$ test) (Figure 1B).

It is possible that the difference in complementation observed between RH-ERP GRA2 and GT1 GRA2 in the plaque assay is due to Toxoplasma killing in MEFs involving other IRG family members in addition to Irgb6. The different IRGs are known to play individual, nonredundant roles during infection, as mice lacking different IRGs exhibit susceptibility to Toxoplasma infection at different stages of infection [50]. Furthermore, Irgb6 coating is likely dependent on proper parasitophorous vacuole biogenesis, which is disrupted in RHAgra2 [35], whereas plaque loss is likely not solely dependent on proper PV biogenesis.

\section{Identification and analysis of differentially expressed parasite genes among type I strains}

In addition to polymorphisms, phenotypic differences between RH-ERP and GT1 can also be attributed to differential expression of parasite genes among the different type I strains. This differential expression could be due to two main reasons [51]. Firstly, polymorphisms in the cis-regulatory regions, such as the promoter or untranslated regions (UTRs), could lead to differences in transcription initiation, transcript stability or transcript decay. Secondly, polymorphic or differentially expressed transcriptional regulators, such as the Apetala 2 (AP2) transcription factors [52], could affect the expression levels of non-polymorphic genes. These transcriptional regulators can affect gene expression levels at different 
Table 3 Top candidate genes that are differentially expressed between RH-ERP and GT1

\begin{tabular}{|c|c|c|c|c|}
\hline \multicolumn{5}{|c|}{ A. Candidate genes containing 5' and 3' UTR SNP/indels and are differentially expressed between RH-ERP and GT1 } \\
\hline Position & ToxoDB GT1 ID & ToxoDB annotation & $\begin{array}{l}\text { Fold change RH-ERP/ GT1 } \\
\text { (Microarray) }\end{array}$ & $\begin{array}{l}\text { Possible involvement in } \\
\text { Toxoplasma process }\end{array}$ \\
\hline $5^{\prime}$ UTR & TGGT1_041490 & dihydrolipoamid dehydrogenase, putative & 1.7 & Growth \\
\hline $5^{\prime}$ UTR & TGGT1_027570 & microneme protein, putative & 1.6 & Invasion \\
\hline 3' UTR & TGGT1_114880 & tRNA splicing 2' phosphotransferase, putative & 1.6 & Translation \\
\hline $5^{\prime}$ UTR & TGGT1_090150 & NBP2B protein, putative & 1.6 & Unknown \\
\hline $5^{\prime}$ UTR & TGGT1_073790 & transporter, major facilitator family protein & -5.1 & Growth \\
\hline \multicolumn{5}{|c|}{ B. Candidate genes consistently differentially expressed between RH-ERP and GT1 } \\
\hline \multicolumn{2}{|c|}{ ToxoDB GT1 ID } & ToxoDB annotation & $\begin{array}{l}\text { Fold change RH-ERP/GT1 } \\
\text { (Microarray) }\end{array}$ & $\begin{array}{l}\text { Possible involvement in } \\
\text { Toxoplasma process }\end{array}$ \\
\hline \multicolumn{2}{|c|}{ TGGT1_098460 } & ankyrin repeat-containing protein & 12.1 & Transcriptional control \\
\hline \multicolumn{2}{|c|}{ TGGT1_073210 } & hypothetical protein & 5.7 & Unknown \\
\hline \multicolumn{2}{|c|}{ TGGT1_020630 } & hypothetical protein (contains glycosyltransferase 17 family) & 5.7 & Unknown \\
\hline \multicolumn{2}{|c|}{ TGGT1_051960 } & $\begin{array}{l}\text { ABC transporter transmembrane region domain-containing } \\
\text { protein }\end{array}$ & 3.0 & Growth \\
\hline \multicolumn{2}{|c|}{ TGGT1_030200 } & Peptidyl-tRNA hydrolase PTH2 domain-containing protein & 2.3 & Growth \\
\hline \multicolumn{2}{|c|}{ TGGT1_000480 } & GRA12 homologue & 2.0 & Growth \\
\hline \multicolumn{2}{|c|}{ TGGT1_126470 } & hypothetical protein & -2.1 & Unknown \\
\hline \multicolumn{2}{|c|}{ TGGT1_048210 } & rhoptry kinase family protein ROP38 (ROP38) & -3.7 & Host cell modulation \\
\hline \multicolumn{2}{|c|}{ TGGT1_047990 } & rhoptry kinase family protein ROP29 (ROP29) & -4.0 & Host cell modulation \\
\hline \multicolumn{2}{|c|}{ TGGT1_081480 } & zinc finger (CCCH type) motif-containing protein & -8.0 & Transcriptional control \\
\hline \multicolumn{2}{|c|}{ TGGT1_021770 } & microneme protein, putative & -9.2 & Invasion \\
\hline \multicolumn{2}{|c|}{ TGGT1_126670 } & rhoptry protein ROP8 (ROP8) & -11.3 & Host cell modulation \\
\hline
\end{tabular}

(A) Candidate genes that have a SNP/indel present in 1000 bp region upstream of predicted ATG start or downstream of predicted end codon, and leading to expression differences of $\geq 1.5$ fold in Toxoplasma arrays. (B) Candidate genes that are consistently differentially expressed between RH-ERP and GT1 using the three Toxoplasma array datasets, but not necessarily containing SNPs/indels in the 5' or 3' UTR regions.

levels of RNA metabolism, such as controlling the formation of the exon junction complex, the export of mRNA through the nuclear complex and translation initiation $[36,52,53]$.

Since sequence variation in promoter regions between strains could lead to differential gene expression, we determined whether any of the 1164 SNPs/indels we identified outside predicted gene coding regions were inside a promoter/5' UTR (defined as 1000 bp upstream of predicted ATG start codon) or 3' UTR (defined as 1000 bp downstream of predicted end codon). We found 133 SNPs/indels within the 5' UTR of 110 genes and 143 SNPs/indels within the 3' UTR of 106 genes. Of these 216 genes with $5^{\prime}$ or $3^{\prime}$ UTR SNPs/indels, microarray analyses showed that 43 genes were $\geq 1.5$ fold differentially expressed between RH-ERP and GT1 (p-value = 0.07, hypergeometric test) (Additional file 1: Table S1).

We identified a putative dihydrolipoamid dehydrogenase (TGGT1_041490) with a 5' UTR polymorphism, that was expressed 1.7 fold higher in RH-ERP compared to GT1 using array data, and was also expressed higher than in other canonical strains such as PRU and VEG (ToxoDB. org). Moreover, this same putative dihydrolipoamid dehydrogenase was expressed approximately 11 fold higher in RH-ERP intracellular parasites compared to extracellular parasite (Table 3A and Additional file 1: Table S1), which could indicate a possible role in intracellular growth. Dihydrolipoamide dehydrogenase serves as a component of several multifunctional complexes, such as pyruvate dehydrogenase, the glycine cleavage system and branched chain amino acid dehydrogenase complexes [54]. Thus, increased expression of this gene in RH-ERP could lead to differences in glycolytic metabolism, or resistance to reactive nitrogen intermediates. Interestingly, deletion of dihydrolipoamide dehydrogenase in an intracellular bacterial pathogen, Mycobacterium tuberculosis, causes a significant attenuation of virulence in mice [55].

Notably, there was a single $A B C$ transporter (TGGT1_025370, also called TgABCG 107 [56]) with a 5' UTR polymorphism, though it was only expressed 1.3 fold higher in RH-ERP compared to GT1 using array data. It was shown that cells transfected with $\operatorname{TgABCG}_{107}$ accumulated larger amounts of cholesterol in an ATPdependent manner compared to untransfected cells, indicating a role for $\mathrm{ABCG}_{107}$ in lipid homeostasis in Toxoplasma [56]. In addition, we noted an ATP 

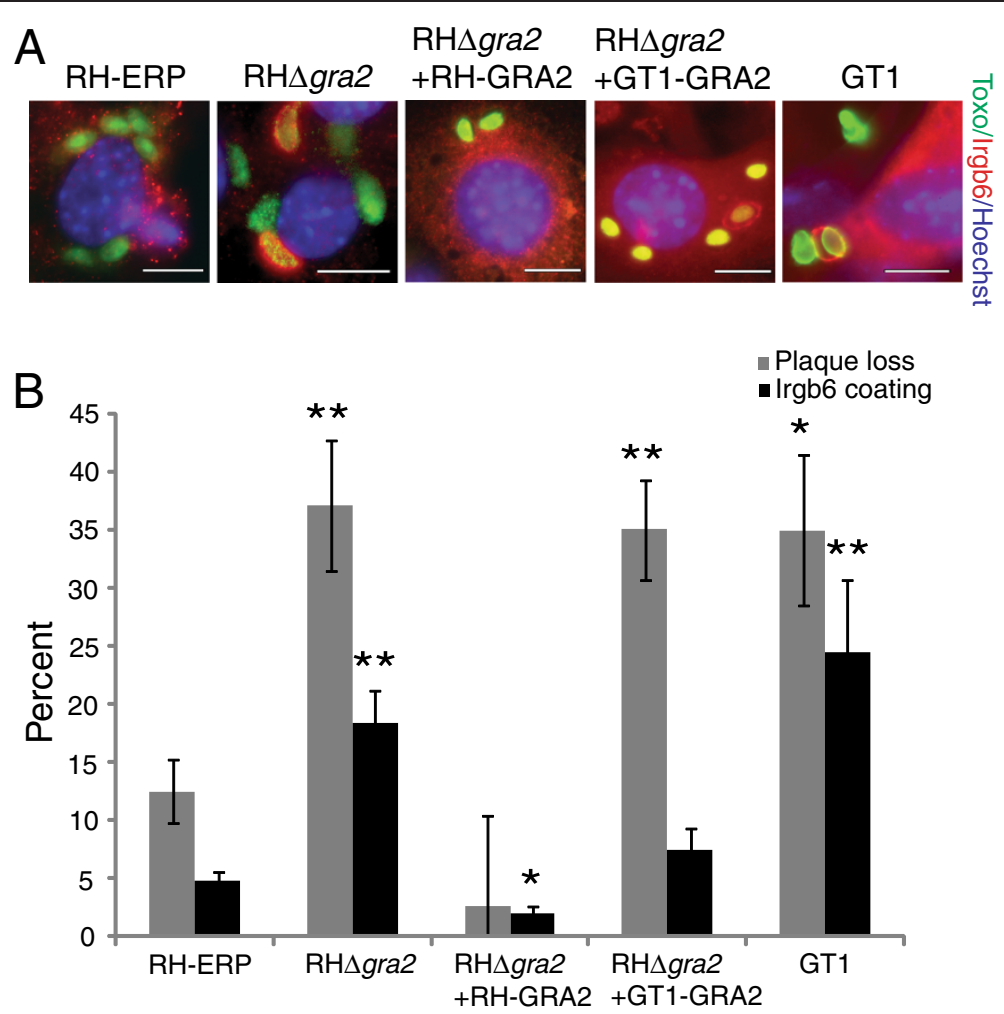

Figure 1 Differences in complementation of plaque loss and Irgb6 coating between RH-ERP and GT1 GRA2. (A) Mouse embryonic fibroblasts were stimulated with IFNy for 24 hours, infected with RH-ERP, RH $\Delta$ gra2, RH $\Delta$ gra2+RH-ERP-GRA2, RH $\Delta$ gra2+GT1-GRA2 and GT1 for 1 hour and stained for Irgb6 (red), Hoechst (blue) and SAG1 (RH-ERP, RHAgra2 and GT1) or TdTomato (complemented strains) (green). Scale bars represent $10 \mu \mathrm{m}$. (B) Quantification of Irgb6 localization on the parasite containing vacuole and percentage plaque loss after 4-7 days on IFNY stimulated MEFs compared to unstimulated MEFs. Mean + SEM, of at least 4 independent experiments, ${ }^{*} p$-value $<0.05$ and ${ }^{* *} p$-value $<0.01$, Student's t-test compared to RH-ERP infected MEFs.

dependent helicase (TGGT1_113930) with a 5' UTR polymorphism that was expressed 1.4 fold higher in RH-ERP compared to GT1 using array data (Additional file 1: Table S1). Thus, overexpression of these ATP dependent candidate genes identified could contribute to the enhanced growth of RH-ERP.

Interestingly, we identified an AP-2 transcription factor (AP2VIIA2; TGGT1_072850) with a 3' UTR polymorphism, and is more highly expressed in M4 in vitro bradyzoites and in vivo cysts compared to in vitro tachyzoites [46] (Additional file 1: Table S1). 24 AP-2 transcription factors have cyclical expression profiles corresponding to the tachyzoite division cycle, whereas 11 AP-2 mRNAs are induced during in vitro bradyzoite differentiation (including AP2VIIA2) [52]. Therefore, this AP2 transcription factor could be involved in the regulation of genes required for bradyzoite differentiation and cyst formation.

Another reason for differential parasite gene expression could be polymorphic or differentially expressed trans-regulators, such as the AP2 transcription factors [52] that could regulate the expression of many nonpolymorphic genes. Alternatively, differential expression of genes could be under epigenetic control, such as post translational modification of histone proteins or arginine methylation [57,58]. Thus, we investigated genes that were differentially expressed between RH-ERP, RH-JSR and GT1, regardless of SNPs in the coding or regulatory regions (Additional file 3: Table S2). We used expression datasets available from a previous published study [15], another independent dataset with parasite gene expression levels comparing RH-ERP and GT1 [22], and our own Toxoplasma arrays measuring parasite gene expression levels comparing RH-ERP, RH-JSR and GT1 (GSE44191). We analyzed for transcripts that were $\geq 1.5$ fold differentially expressed between RH-ERP and GT1 across these three datasets, to identify genes that were consistently up or downregulated between RH-ERP and GT1. We identified 13 transcripts that had consistently increased and 13 transcripts that had consistently decreased expression in RH-ERP compared to GT1 across all three independent datasets respectively.

From the 13 consistently upregulated transcripts in RH-ERP compared to GT1 (Additional file 3: Table S2), we identified a putative ankyrin repeat containing protein (TGGT1_098460). This gene was highly expressed in RH-ERP in both array and RNA-seq datasets, but not 
in GT1 (Table 3B), and had lower expression in canonical strains such as PRU and VEG (ToxoDB.org). Ankyrin repeats mediate molecular recognition via protein-protein interactions [59], and proteins containing these repeats are involved in a large number of cellular functions, ranging from modulation of the NF-kB response to transcriptional regulation [60]. Interestingly, TgANK-1, a parasite protein containing ankyrin repeats, is induced upon bradyzoite differentiation using $\mathrm{RH}$ parasites, and localizes to the parasite cytosol [61]. Another gene that was consistently upregulated was a GRA12 homologue, and GRA12 co-localizes with GRA2 and interacts with GRA2 or GRA2-associated proteins [62]. Therefore, this gene could be associated with the increased growth rate of $\mathrm{RH}$ ERP compared to GT1.

Of the 13 transcripts with increased expression in GT1 compared to RH-ERP, three encode for known rhoptry proteins, ROP8 (TGGT1_126670), ROP29 (TGGT1_047990) and ROP38 (TGGT1_048210) (Table 3C). ROP29 and ROP38 are part of a repeated gene family, and overexpression studies of ROP38 in the RH-ERP background showed that ROP38 has major effects on host gene expression [63]. Furthermore, as ROP8, ROP29 and ROP38 have predicted signal peptides, these rhoptry proteins might be involved in differential host modulation between RH-ERP and GT1. Several rhoptry proteins are known to be secreted into the host cells, where they play major roles in modulation of the host cell functions [64].

\section{Differentially modulated parasite pathways between type I strains}

In addition, we analyzed whether the differentially expressed genes between RH-ERP, RH-JSR and GT1 across the three independent datasets were enriched in annotated biological functions [65]. We focused on functional enrichment of parasite genes differentially expressed in RH-ERP compared to RH-JSR and GT1, using our own arrays and expression data from previous studies [15,22]. There were 15 Gene Ontology (GO) and 25 InterPro genesets that were significantly enriched in RH-ERP compared to RH-JSR/GT1 (false discovery rate (FDR) < 0.10). Parasite genes differentially expressed in RH-ERP compared to RH-JSR/GT1 were enriched in GO processes such as transcription, translation, protein folding and ironsulfur cluster binding (Figure 2A and Additional file 4: Table S3). Similarly, parasite genes differentially expressed in $\mathrm{RH}$-ERP compared to RH-JSR/GT1 were enriched in InterPro domains such as peptidyl-prolyl cis-trans isomerases, cyclophilin-like and DNA-dependent RNA polymerases (Figure 2B and Additional file 4: Table S3). This is in accord with observations that RH-ERP has a higher growth rate, likely requiring increased transcription and translation, and increased extracellular viability [15], likely requiring expression of stress proteins to survive extracellular stress.

\section{Differential modulation of host pathways between type I strains}

Because some of the differentially expressed or polymorphic Toxoplasma genes, such as ROP38, might be involved in the modulation of host cell signaling pathways [63], we determined whether different type I strains differ in their ability to modulate the host cell response. To do this, we infected HFFs with RH-ERP, RH-JSR and GT1 for 24 hours and determined host gene expression profiles using microarrays. We identified 146, 95, and 253 host transcripts that were consistently up/downregulated $\geq 1.5$ fold in every experiment comparing RH-ERP against GT1, RH-ERP against RH-JSR and RH-JSR against GT1 respectively (Figure 3A and Additional file 5: Table S4). As ROP38 was differentially expressed between RH-ERP and GT1, and has major effects on host gene expression, we wanted to determine the effects of ROP38 in differentially expressed host transcripts between RH-ERP and GT1. To do this, we used expression datasets available from a previous study that compared host gene expression after infection with RH-ERP or RH-ERP overexpressing ROP38 [63]. From the 146 host transcripts that were consistently differentially expressed between RH-ERP and GT1, 14 were also $\geq 1.5$ fold differentially expressed between $\mathrm{RH}$ and $\mathrm{RH}$ overexpressing ROP38 (Additional file 5: Table S4). Thus, these 14 genes which are differentially expressed between RH-ERP and GT1 could be due to ROP38 expression differences.

We subsequently determined if the promoters of the consistently differentially regulated host genes were enriched for specific transcription factor binding sites (TFBS) [30,31]. We noted an NF-kB signature in the promoter of host genes that were upregulated $\geq 1.5$ fold in GT1 compared to RH-ERP (Figure 3B), and also noted that type I interferon and STAT1 signatures were present in host genes upregulated in HFFs infected with GT1 compared to RH-ERP. In addition, we observed STAT6 enrichment in the promoter of host genes that were consistently upregulated in RH-JSR compared to RH-ERP (Additional file 6: Table S5).

\section{NF-KB activation and induction of IL-12p40 secretion upon infection are differentially modulated by type I strains and are dependent on GRA15}

Previous studies have shown that type II strains activate NF- $\mathrm{kB}$ to a much higher level compared to types I and III, and this difference is due to polymorphisms in the dense granule protein, GRA15 [23]. It was noted that high levels of nuclear translocation of the p65 subunit of NF- $\kappa B$ were present in host cells infected with several type II strains (ME49, PRU, DAG and Beverly), while 
A GSEA Gene Ontology en richment for differentially expressed parasite genes in RH-ERP compared to RH-JSR/GT1

\begin{tabular}{c|c}
\hline Gene Ontology Pathway & FDR q-value \\
\hline Protein folding & 0.02 \\
Structural constituent of ribosome & 0.02 \\
Iron sulfur cluster binding & 0.03 \\
Peptidyl prolyl cis-trans isomerase activity & 0.03 \\
Cellular components associated with the ribosome & 0.03
\end{tabular}
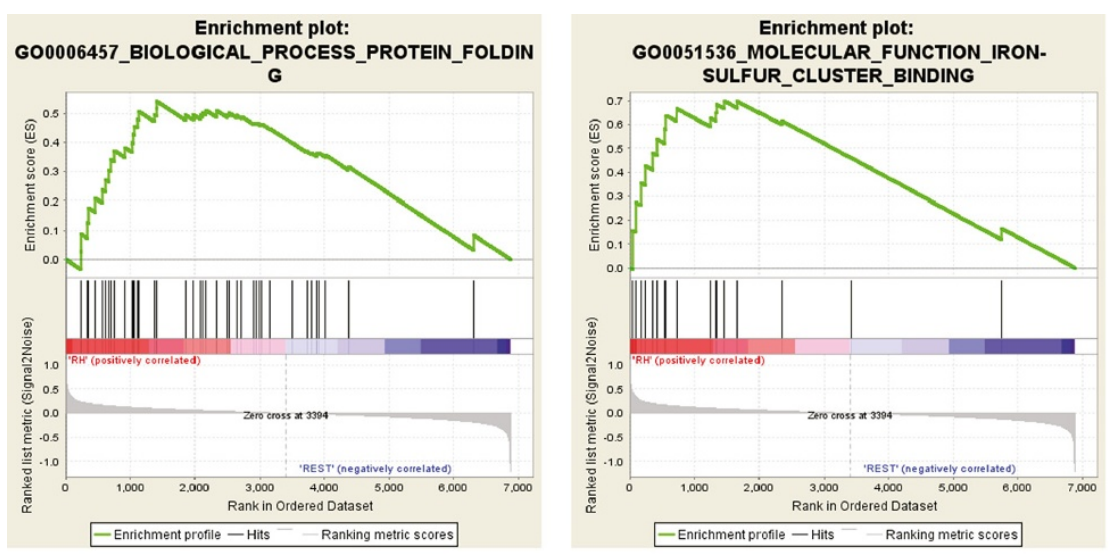

B GSEA InterPro en richment for differentially expressed parasite genes in $\mathrm{RH}$-ERP compared to RH-JSR/GT1

\begin{tabular}{c|c}
\hline InterPro Domain & FDR q-value \\
\hline Cyclophilin-like & 0.001 \\
Cyclophilin type peptidyl prolyl cis-trans isomerase & 0.001 \\
Translation & 0.02 \\
Transcription, DNA-dependent & 0.03 \\
SNARE-like & 0.03
\end{tabular}
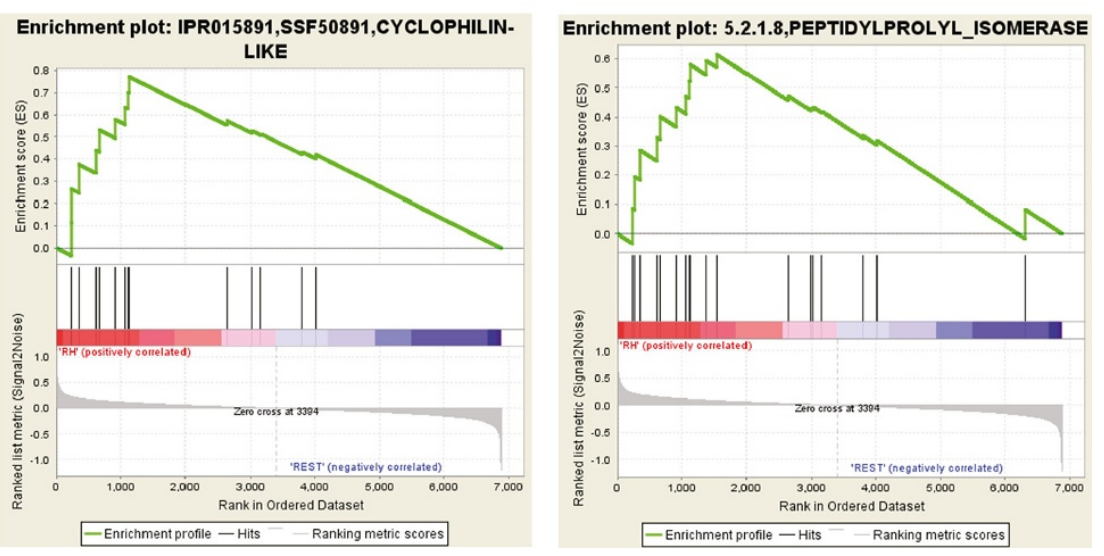

Figure 2 (See legend on next page.) 
(See figure on previous page.)

Figure 2 Differential parasite gene expression between type I strains. (A) The top five enriched Gene Ontology (GO) pathways using GSEA in differentially expressed parasite genes in RH-ERP compared to RH-JSR/GT1 and the corresponding GSEA diagrams, using Toxoplasma genesets with Gene Ontology annotations. The GSEA diagrams show the enrichment score (green line), which reflects the degree to which that particular gene set (header above) is overrepresented in the differentially expressed genes between RH-ERP and RH-JSR/GT1 (ranked by their differential expression values). The middle portion of the diagram shows where the members of the particular gene set appear in the ranked gene list. The bottom portion of the diagram shows the value of the ranking metric, which measures the correlation of a gene with upregulation (positive value) or downregulation (negative value) in RH-ERP compared to RH-JSR/GT1. (B) The top five enriched InterPro domain using GSEA in differentially expressed parasite genes in RH-ERP compared to RH-JSR/GT1 and the corresponding GSEA diagrams, using Toxoplasma genesets with InterPro annotations.

host cells infected with RH-ERP and GT1 had much lower levels of p65 translocation [23]. Our host transcriptional profile analysis across the type I strains indicated that there is an enrichment in NF- $\mathrm{kB}$ binding sites in the promoters of host genes that are more highly induced by GT1 infection compared to RH-ERP (Figure 3B). To validate this analysis, HEK293T NF-kB reporter cells with NF- $\mathrm{kB}$ binding sites driving the expression of GFP and luciferase were infected with $\mathrm{RH}$ ERP, RH-JSR and GT1 for 24 hours and assayed for NF- $\mathrm{KB}$ dependent luciferase activity (Figure 4A). In accord with the transcriptional profiling analysis, GT1 infection induced much higher NF- $\mathrm{BB}$ mediated luciferase activity compared to RH-ERP ( $p$-value $=0.001$, Student's $t$ test), although this induction was still 2-3 fold lower compared to cells infected with Pru, a type II strain (data not shown).

We then investigated whether GRA15 could explain the differences in NF- $\mathrm{kB}$ activation between the type I strains, since our SNP analysis indicated an indel in GRA15 when comparing RH-ERP and GT1 (Additional file 1: Table S1). Moreover, RH-ERP was shown to contain a frameshift deletion compared to GT1, leading to a nonfunctional GRA15 in RH-ERP [23]. Because RH-JSR also does not induce NF- $\mathrm{KB}$ activation, we sequenced GRA15 from RH-JSR and, surprisingly, we found that
RH-JSR contains a frameshift insertion at base 734. This mutation is independent from the RH-ERP frameshift deletion at base 872 . The RH-JSR insertion causes a mutation of a stretch of 34 amino acids followed by a premature stop codon (Additional file 7: Figure S2). Thus, both RH-ERP and RH-JSR contain truncated GRA15 proteins of 312 and 278 amino acids respectively, while GT1 has the full length protein of 635 amino acids. GRA15 was observed to affect parasite growth both in vitro and in vivo, as RH-ERP expressing GRA15 ${ }_{\text {II }}$ has reduced plaque size in HFFs and reduced parasite burden in mice [23]. Thus, there could have been a selective pressure for a nonfunctional GRA15 in RH-ERP and RH-JSR, allowing for increased parasite burden in the host or faster replication in vitro.

Since RH-ERP provides a null genetic background with respect to GRA15, we generated transgenic RH-ERP parasites overexpressing GRA15 from GT1 and assayed for NF- $\kappa B$ mediated luciferase activity using the same NF$\kappa \mathrm{B}$ reporter cell line described above (Figure $4 \mathrm{~A}$ ). The NF- $\kappa B$ reporter luciferase activity after infection with RH-ERP+GRA $15_{\text {GT1 }}$ was significantly higher than the activity after infection with RH-ERP ( $p$-value $=0.0001$, Student's $t$ test). This data supports the hypothesis that differences in NF- $\mathrm{kB}$ activation among type I strains are due to GRA15. In addition, the NF- $\mathrm{BB}$ family of

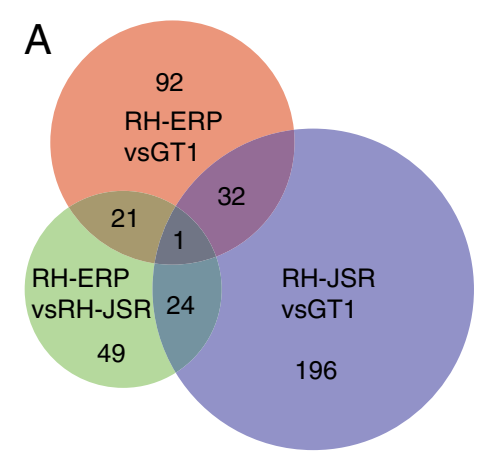

\begin{tabular}{c|c} 
B $\begin{array}{c}\text { Consistently upregulated host genes in } \\
\text { GT1 infected HFFs compared to RH-ERP }\end{array}$ \\
\hline $\begin{array}{c}\text { Transcription } \\
\text { factor }\end{array}$ & Importance \\
\hline NFKAPPAB & 0.25 \\
ISRE & 0.20 \\
STAT1 & 0.18 \\
NFE2 & 0.15 \\
IRF7 & 0.10
\end{tabular}

Figure 3 Differential host gene expression between type I strains. HFFs were infected for 24 hours with RH-ERP, RH-JSR and GT1 and host gene expression was analyzed using microarrays. Three arrays were done per strain for RH-ERP and RH-JSR, and two arrays were done for GT1. (A) Venn diagram showing the number of host genes that were consistently differentially expressed $\geq 1.5$ fold or more for each pairwise comparison between type I strains. (B) Top five enriched known transcription factors from DiRE analysis of consistently upregulated host genes in GT1 infection compared to $\mathrm{RH}$-ERP. 

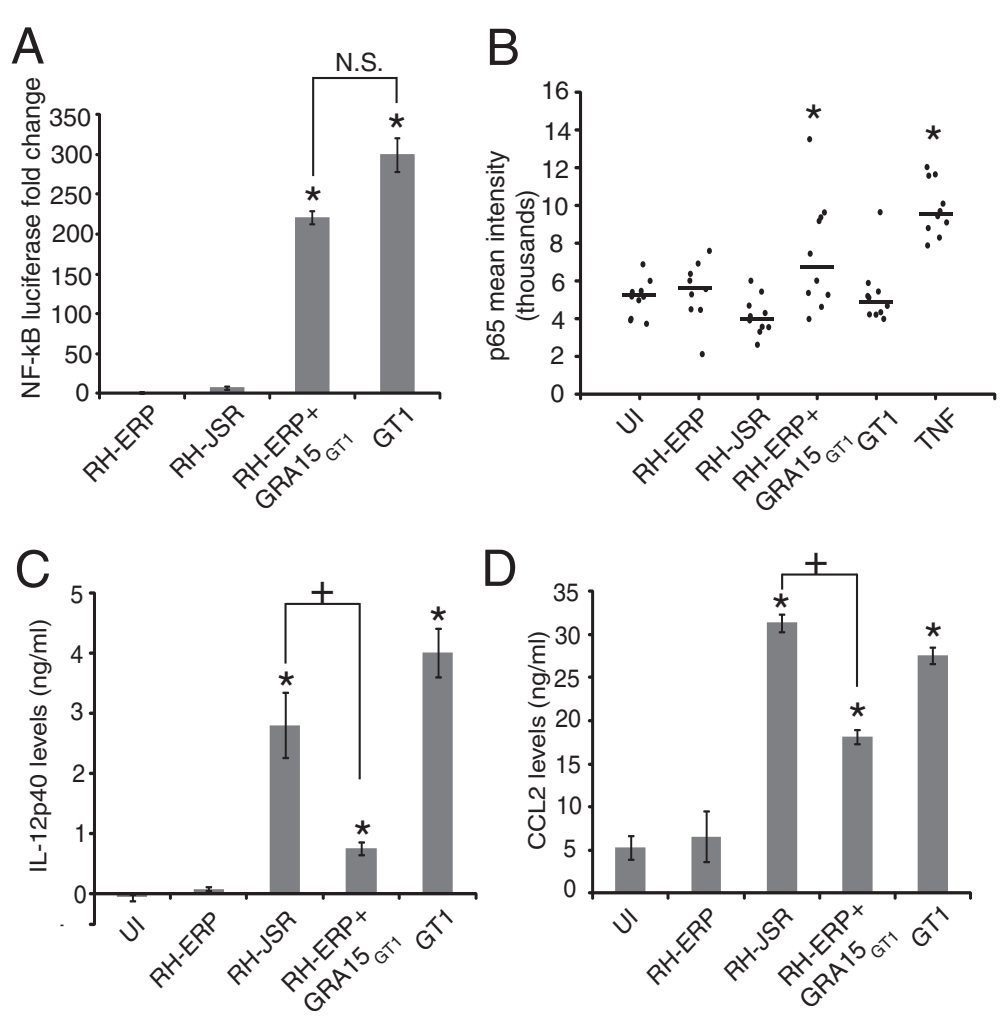

Figure 4 Type I strains differentially activate NF-kB nuclear translocation, and is dependent on GRA15. (A) HEK293T NF-kB reporter cells were infected with RH-ERP, RH-JSR, RH+GRA15 $5_{\mathrm{GT} 1}$ and GT1. For each strain, the luciferase reading after 24 hours infection was taken. The graph shows averages from three independent experiments, with levels representing fold change of NF-kB luciferase readings normalized to uninfected, unstimulated control cells, and the error bars represent the standard error. Mean + SEM, of three experiments, ${ }^{*} p$-value $<0.01$, N.S. not significant, Student's t-test. (B) HFFs were infected for $24 \mathrm{~h}$ with RH-ERP, RH-JSR, GT1 and RH+GRA15 GT1 transgenic, uninfected cells were stimulated with TNF-alpha for $1 \mathrm{~h}$ (TNF), or left unstimulated and uninfected (UI). Cells were fixed, probed with p65 antibody and mean nuclear staining was quantified, the error bars represent the standard deviation, * $p$-value $<0.05$, Student's $t$-test. Quantification shown is representative of three independent experiments. (C) IL12-p40 and (D) CCL2 levels were measured in supernatants from C57BL/6 bone marrow derived macrophages infected for 24 hours with RH-ERP, RH-JSR, RH+GRA15 $5_{\mathrm{GT} 1}$ transgenic and GT1. The graphs shown are representative of three independent experiments for IL-12p40 and two independent experiments for CCL2, and the error bars represent the standard deviation, * $p$-value $<0.01$, Student's $t$-test between strain and RH-ERP infected BMMs, $+p$-value $<0.01$, Student's $t$-test between the two conditions indicated.

transcription factors consist of five members, p65, c-REL, REL-B, p50 and p52 [66], and the NF- $k B$ reporter contains four repeated, canonical NF- $\mathrm{kB}$ binding sites which can be bound by the different NF-kB subunits. Previous studies showed p65 nuclear localization in host cells infected with type II strains [23] and we wanted to determine whether p65 nuclear translocation could be responsible for differential NF-kB activation observed in host cells infected by GT1 compared to RH-ERP. HFFs were infected with RHERP, RH-JSR, GT1 or transgenic RH-ERP+GRA15 $5_{\mathrm{GT} 1}$, and nuclear localization of p65 was examined by immunofluorescence (Figure 4B). There was significant nuclear translocation of p65 in cells infected with transgenic RH-ERP+GRA15 ${ }_{\mathrm{GT} 1}$ parasites compared to uninfected cells ( $p$-value $=0.02$, Student's $t$ test), but no significant $\mathrm{p} 65$ nuclear translocation was observed in cells infected with RH-ERP and GT1 ( $p$-value $>0.05$, Student's $t$ test). It is possible that the GRA15 in GT1 activates a different NF- $\mathrm{KB}$ subunit from $\mathrm{p} 65$, such as c-REL or p50, but transgenic high overexpression of GRA15 ${ }_{\mathrm{GT} 1}$ in RH-ERP activates p65 in addition to other subunits. It is also possible that there are other GT1 genes that could have an inhibitory effect on p65 translocation.

GRA15 from type II strains (GRA15 II) was also shown to affect levels of IL-12p40, a NF-kB dependent cytokine, by infected macrophages in vitro [23], and regulation of IL12-p40 production has been linked to NF- $\mathrm{kB}$ activation [67]. Thus, we investigated whether type I strains differ in their ability to induce secretion of IL-12p40 and CCL2, another NF-кB dependent cytokine, and examined whether GRA15 from GT1 played a role in these differences. GT1 infection of C57BL/6 bone marrow derived macrophages resulted in secretion of higher levels of both IL-12p40 and CCL2 in culture supernatants compared to RH-ERP infection (Figures $4 \mathrm{C}$ and $4 \mathrm{D}$, 
$p$-value $=7.5 \times 10^{-5}($ IL-12p40) and $p$-value $=0.0003$ (CCL2), Student's $t$ test). This phenotype can be partially attributed to GRA15, as macrophages infected with RH-ERP+GRA15 ${ }_{\mathrm{GT}}$ induced higher levels of IL-12p40 and CCL2 compared to RH-ERP (Figure 4C and 4D, $p$-value $=0.0006(\mathrm{IL}-12 \mathrm{p} 40)$ and $p$-value $=0.003$ (CCL2), Student's $t$-test). However, GRA15 ${ }_{\mathrm{GT} 1}$ in the $\mathrm{RH}+\mathrm{GRA} 15_{\mathrm{GT} 1}$ background was not sufficient to increase secretion of IL12-p40 by infected macrophages to levels comparable to those observed in macrophages infected with GT1. Moreover, infection with RH-JSR, which has a nonfunctional GRA15, induced IL12-p40 to levels higher than infection with RH-ERP+GRA15 $5_{\mathrm{GT}}$ $\left(p\right.$-value $=0.003\left(\right.$ IL12-p40) and $p$-value $=5.9 \times 10^{-5}$ (CCL2), Student's $t$-test). Therefore, it is likely that other Toxoplasma genes contribute to induction of IL-12p40 and CCL2 production by infected macrophages, especially given that the regulation of IL12-p40 is more complex than sole control by NF-kB [68].

\section{Localization of $\mathrm{p}-\mathrm{IkBa}$ at the PVM is strain specific, independent of NF-kB activation and partially dependent on GRA2}

In the canonical NF- $\mathrm{kB}$ activation pathway, I $\mathrm{K} \mathrm{B} \alpha$ normally inhibits NF- $\mathrm{kB}$ translocation and sequesters NF- $\mathrm{kB}$ in the cytoplasm. However, upon stimulation, IKB $\alpha$ is phosphorylated and subsequently targeted for proteasomal degradation via ubiquitination, exposing the nuclear localization signal in NF- $\mathrm{kB}$ and allowing nuclear localization to occur [66]. It has been previously reported that phospho-IкB $\alpha$ $(\mathrm{p}-\mathrm{I} \kappa \mathrm{B} \alpha)$ is localized to the PVM in RH-ERP infected mouse embryonic fibroblasts (MEFs), and this has been linked to NF-kB activation [69,70]. However, there was little or no $\mathrm{p}$-ІкB $\alpha$ localization at the PVM in cells infected with type II and type III strains [23]. Moreover, localization of $\mathrm{p}$-I $\mathrm{K} \mathrm{B} \alpha$ was observed using RH-ERP, and it is currently unknown whether the same phenomenon holds true for other type I strains.

Thus, to determine whether $\mathrm{p}$-IкB $\alpha$ is also redirected to the PVM in cells infected with other type I strains, immunofluorescence (IF) with antibodies against p-IкB $\alpha$ was performed in HFFs infected with RH-ERP, RH-JSR and GT1. In agreement with previous studies, p-IкB $\alpha$ localized to the PVM of RH-ERP, but there was much less accumulation of p-IKB $\alpha$ at the PVM in HFFs infected with other type I strains (Figure 5A). Quantification of the intensity of $\mathrm{p}-\mathrm{I} \mathrm{KB} \alpha$ around the PVM confirmed that vacuoles containing RH-ERP recruited significantly more $\mathrm{p}$-ІкB $\alpha$ than vacuoles with RH-JSR or GT1 (Figure 5B, $p$-value $=$ 0.009 (RH-JSR) and 0.008 (GT1), Student's $t$-test). It is unlikely that NF-kB activation levels are correlated with the level of $\mathrm{p}-\mathrm{I} \kappa \mathrm{B} \alpha$ recruitment around the PVM, given previous data that type II strains activate NF-kB in infected host cells but do not induce accumulation of $\mathrm{p}-\mathrm{I} \kappa \mathrm{B} \alpha$ to the
PVM [23]. This is further supported by the observed differences in type I strains, since neither RH-ERP nor RH-JSR activate NF-kB (Figure 4A) but RH-ERP induces strong accumulation of $\mathrm{p}-\mathrm{I} \kappa \mathrm{B} \alpha$ at the PVM. In addition, localization of $\mathrm{p}-\mathrm{I} \kappa \mathrm{B} \alpha$ was similar in HFFs infected with RH-ERP+GRA15 $5_{\mathrm{GT} 1}$ compared to RH-ERP infected HFFs (data not shown), even though RH-ERP+GRA15 $5_{\mathrm{GT} 1}$ activates NF- $\mathrm{k} B$, which further supports that NF- $\mathrm{kB}$ activation is unrelated to accumulation of $\mathrm{p}-\mathrm{I} \kappa \mathrm{B} \alpha$ on the PVM.

To determine whether accumulation of $\mathrm{p}$-ІкB $\alpha$ at the PVM could be due to a soluble factor secreted by RH-ERP, immunofluorescence was performed in cells co-infected with both RH-ERP and GT1. Recruitment of $\mathrm{p}$-IkB $\alpha$ to the PVM was observed only in vacuoles containing RH-ERP $\left(\mathrm{GFP}^{+}\right)$, whereas little or no $\mathrm{p}$-IkB $\alpha$ was recruited to the GT1 PVM (Figure 5C), implying that p-ІкB $\alpha$ translocation is not induced by soluble secreted parasite factors. We also tested the effect of ROP16, a known secreted rhoptry kinase, on $\mathrm{p}-\mathrm{I} \kappa \mathrm{B} \alpha$ recruitment, and saw no observable differences between RH-ERP and RH $\Delta$ rop 16 (Additional file 8: Figure S3). We also observed that p-IkB $\alpha$ colocalized with GRA7 at PVM extensions (Figure 5D) where another dense granule protein, GRA14, has been described to be trafficked to [71]. Furthermore, as mentioned before, GRA2 is known to affect the vesicular network in the PV and PVM [72,73] and we identified that RH-ERP GRA2 differs in one amino acid from RH-JSR/GT1 GRA2 (Additional file 1: Table S1).

Thus, we examined whether dense granule proteins

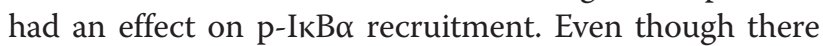
were no observable differences in PVM localization of $\mathrm{p}$-I $\mathrm{K} \alpha \alpha$ between RH-ERP and RH $\Delta$ gra15 (Additional file 8: Figure S3), there was observed reduction of $\mathrm{p}-\mathrm{I} \kappa \mathrm{B} \alpha$ accumulation at the PVM in cells infected with RHAgra2 (Figure 5B). Since the vacuoles formed by the RH $\Delta$ gra 2 exhibit disruptions in the intravacuolar network [35], lack of $\mathrm{p}-\mathrm{I} \kappa \mathrm{B} \alpha$ recruitment to the PVM could be due to disruption of parasitophorous vacuole biogenesis. Alternatively, as GRA2 has been found in complexes with other dense granule proteins [74], these GRA proteins could be directly interacting with host IKB $\alpha$.

In addition, complementation of RH $\triangle g r a 2$ with either RH-ERP GRA2 or GT1 GRA2 partially restored the p-IкB $\alpha$ localization phenotype, with increased PVM recruitment of $\mathrm{p}$-I $\mathrm{K} \mathrm{B} \alpha$ present in both complemented strains compared to RH $\Delta$ gra2 (Additional file 9: Figure S4A). Quantification of the intensity of $\mathrm{p}-\mathrm{I} \kappa \mathrm{B} \alpha$ around the PVM confirmed that both complemented strains did not have significantly different PVM recruitment of $\mathrm{p}-\mathrm{I}_{\kappa} \mathrm{B} \alpha \mathrm{com}$ pared to RH-ERP (Additional file 4: Figure S4B, $p$-value = 0.45 (complemented RH-ERP GRA2) and $p$-value $=0.58$ (complemented GT1 GRA2), Student's $t$-test). This suggests that although GRA2 expression is necessary 


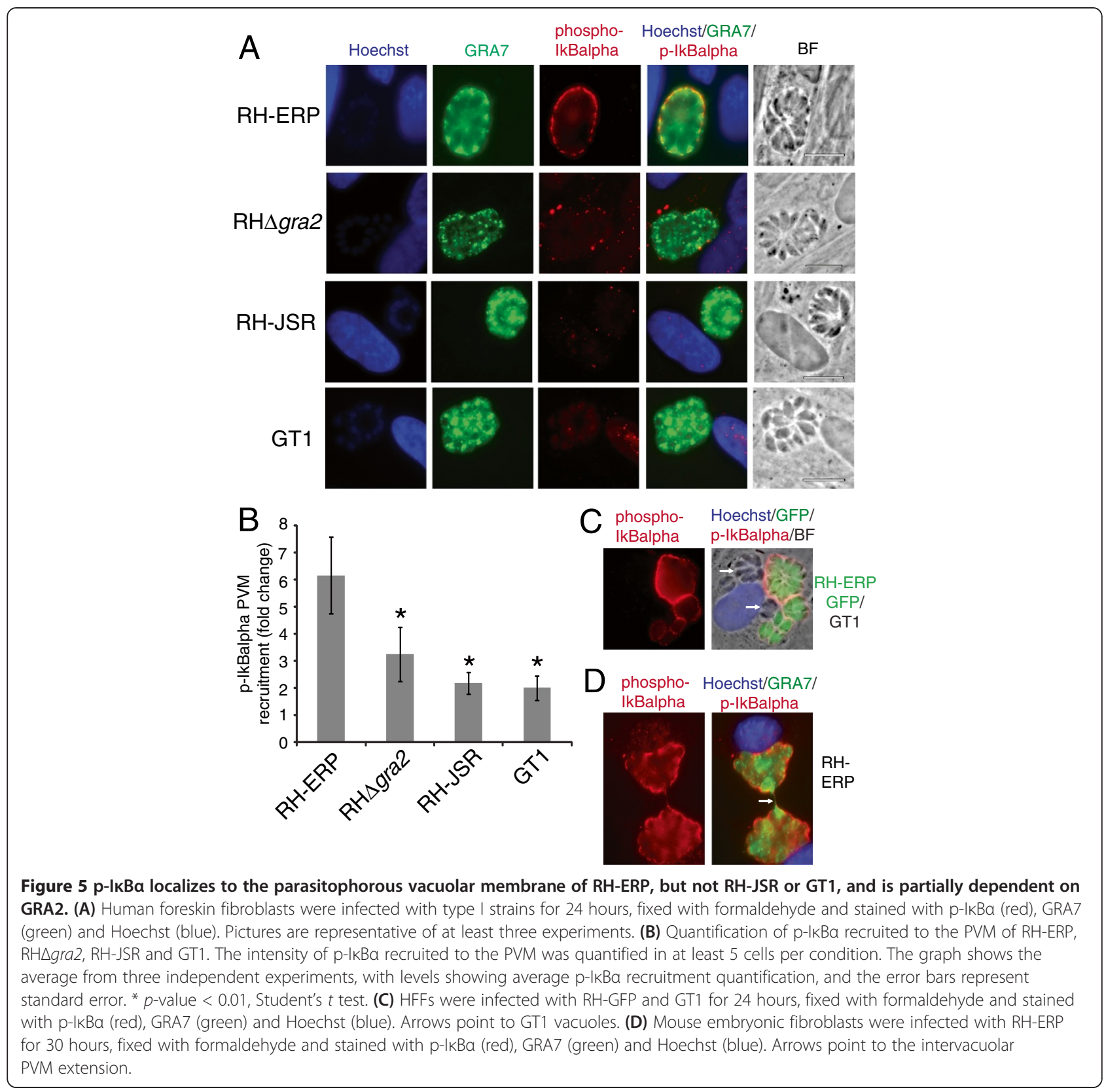

for full accumulation of $\mathrm{p}-\mathrm{I} \mathrm{K} \mathrm{B} \alpha$ to the PVM, it is likely due to proper parasitophorous vacuole biogenesis rather than the specific polymorphism present in GRA2 between RH-ERP and GT1.

\section{Conclusions}

In summary, through comparative genome and gene expression analysis, we identified a list of candidate genes that could be responsible for the phenotypic differences between different type I strains. We show that polymorphisms in GRA2 and GRA15 determine type I strain differences in survival in IFN- $\gamma$ stimulated cells and activation of NF- $\mathrm{kB}$, respectively. Future experiments will focus on the contribution of the individual genes to the increased growth rate, higher extracellular viability and loss of orally infectious cyst formation ability in RHERP. Thus, these identified parasite genes and differentially modulated host pathways could lead to design of new parasite targets relevant to Toxoplasma pathogenesis and chronic infection. However, it is likely that many of these phenotypes are affected by a combination of SNPs/indels and/or expression differences across multiple parasite genes, rather than being controlled by individual or a few genes. 


\section{Availability of supporting data}

The data sets supporting the results of this article are available in the GEO repository as a GEO SuperSeries, GSE44246, http://www.ncbi.nlm.nih.gov/geo/query/acc.cgi? acc=GSE44246.

\section{Additional files}

Additional file 1: Table S1. List of single nucleotide polymorphisms and insertions/deletions present between RH-ERP and GT1 through whole genome sequencing. A total of 1,394 SNPs/indels were identified between RH-ERP and GT1, with 230 SNPs/indels in predicted gene coding regions, 484 SNPs/indels in predicted genes (outside coding regions) and 680 SNPs/ indels outside predicted genes. SNPs/indels with gene IDs have been annotated with ToxoDBv8 descriptions, Toxoplasma arrays for parasite gene expression between RH-ERP, RH-JSR and GT1 [15,22] and RNA-seq data for RH-ERP and GT1. SNPS/indels have also been annotated whether they are present in 1000 bp upstream of predicted ATG start (5'UTR) or 1000 bp downstream of predicted end codon (3'UTR). For SNP/indels in 5' or 3' UTR, the corresponding genes have been annotated with Toxoplasma array parasite gene expression levels and RNAseq data.

Additional file 2: Figure S1. Expression and localization of GRA2 in the $\mathrm{RH} \Delta$ gra2 complemented strains. (A) Immunofluorescence of HA (red) in $\mathrm{RH} \Delta$ gra2 complemented with RH-ERP-GRA2-HA or GT1-GRA2-HA parasites, co-stained with Hoechst (blue) and TdTomato (green). (B) Western blot for HA (top) and SAG1 (bottom) comparing HA expression of RHAgra2 complemented with RH-ERP-GRA2-HA or GT1-GRA2-HA.

Additional file 3: Table S2. Consistently differentially expressed Toxoplasma genes between RH-ERP, RH-JSR and GT1. Parasite transcripts which were consistently differentially expressed $\geq 1.5$ fold between $\mathrm{RH}$-ERP and GT1 in the same direction in two previous studies [15,22] and arrays used in this study were identified. These consistently differentially expressed genes were annotated with whether they had increased or decreased expression in $\mathrm{RH}$-ERP compared to GT1, ToxoDBv8 description, Toxoplasma array parasite gene expression levels and RNAseq data for RH-ERP and GT1.

Additional file 4: Table S3. Differentially modulated Toxoplasma pathways present in RH-ERP compared to RH-JSR and GT1. Parasite transcript expression in RH-ERP, RH-JSR and GT1 in two previous studies $[15,22]$ and in this study were analyzed for enrichment in any one strain using GSEA. Enriched parasite pathways in RH-ERP compared to RH-JSR/GT1, using GO and InterPro annotations, which had a false discovery rate $<0.1$ were identified.

Additional file 5: Table S4. Consistently differentially expressed host genes between RH-ERP, RH-JSR and GT1. Human foreskin fibroblasts were infected for 24 hours with RH-ERP, RH-JSR and GT1, and host gene expression was determined through microarrays. Host transcripts which were consistently differentially expressed $\geq 1.5$ fold between $\mathrm{RH}$-ERP, RH-JSR and GT1 in each pairwise comparison were identified. Consistently differentially expressed host transcripts which were also $\geq 1.5$ fold between $\mathrm{RH}$ and $\mathrm{RH}$ overexpressing ROP38 from a previous study were also identified [63]. Transcripts were annotated with gene description, strand type, GO term function, Gene Symbol and RefSeq IDs from the HG18 database.

Additional file 6: Table S5. DiRE transcription factor binding site analysis of consistently differentially regulated host genes between type I strains. Host genes which were consistently differentially expressed $\geq 1.5$ fold in each type I strain in a pairwise comparison were subject to TFBS analysis by DiRE. The top 10 TFs (with importance value $>0.1$ ) associated with upregulated or downregulated host genes for a particular pairwise comparison are shown.

Additional file 7: Figure S2. Differences in GRA15 sequence between $\mathrm{RH}$ ERP, RH-JSR and GT1. RH-JSR and RH-ERP contain indels at position 734 and 872 respectively, which lead to independent frameshifts and early stop codons in the GRA15 protein. Dots represent consensus with the GT1 GRA15 sequence, dashes represent missing amino acids in RH-ERP or RH-JSR GRA15 compared to GT1 GRA15, red indicate amino acids different in RH-ERP from GT1 and purple indicate amino acids different in RH-JSR from GT1.
Additional file 8: Figure S3. No differences in PVM localization of $\mathrm{p}-\mathrm{K} \mathrm{KBa}$ present between $\mathrm{RH}-\mathrm{ERP}, \mathrm{RH} \Delta$ rop 16 and $\mathrm{RH} \Delta$ gra15. Human foreskin fibroblasts were infected with $\mathrm{RH}-\mathrm{ERP}$ and knockout strains at intended $\mathrm{MO}$ 1 for 30 hours, fixed with formaldehyde and stained with $p-1 k B a(r e d)$, GRA7 (green) and Hoechst (blue). Pictures are representative of at least two experiments.

Additional file 9: Figure S4. Partial restoration in PVM localization of $\mathrm{p}$ IKBa present in RH $\triangle$ GRA2 complemented with either RH-ERP GRA2 or GT1 GRA2. (A) Human foreskin fibroblasts were infected with RH $\triangle$ gra2, $\mathrm{RH} \triangle$ gra2 complemented with either RH-ERP GRA2 or GT1 GRA2 for 30 hours, fixed with methanol and stained with p-IkBa (red), GRA7 (green) and Hoechst (blue). Pictures are representative of three experiments. (B) Quantification of $\mathrm{p}-\mathrm{I} \mathrm{kBa}$ recruited to the PVM of RH-ERP, RH $\triangle$ gra2 and $\mathrm{RH} \triangle \mathrm{gra} 2$ complemented with either RH-ERP GRA2 or GT1 GRA2. The intensity of $\mathrm{p}-\mathrm{K} \mathrm{KBa}$ recruited to the PVM was quantified in at least 5 cells per condition. The graph shows the average from three independent experiments, with levels showing average $\mathrm{p}-\mathrm{k} \mathrm{kBa}$ recruitment quantification, and the error bars represent standard error. ${ }^{*} p$-value < 0.01 , Student's $t$ test.

\section{Abbreviations}

EGR: Early growth response factor; FDR: False discovery rate; GRA: Dense granule protein; HFF: Human foreskin fibroblast; IRG: Immune related GTPase; Indels: Insertions/deletions; IkBa: Inhibitor of Nuclear factor kappa-lightchain-enhancer of activated B cells; MEF: Mouse embryonic fibroblast; NF-kB: Nuclear factor kappa-light-chain-enhancer of activated B cells; PVM: Parasitophorous vacuole membrane; ROP: Rhoptry protein; SNP: Single nucleotide polymorphism; SRF: Serum response factor; UTR: Untranslated region.

\section{Competing interests}

The authors declare that they have no competing interests.

\section{Authors' contributions}

JPJS and NY analyzed the sequencing and parasite/host gene expression data. NY performed luciferase assays, immunoassays and $\mathrm{p}-\mathrm{I} \mathrm{kBa}$ immunofluorescence assays. AF, GTM and MJG performed, processed and annotated the sequencing data between RH-ERP and GT1. WN made the GRA2 complemented strains and performed plaque assays and IRG evasion. MM contributed RNA-seq data for RH-ERP and GT1. DL and $L J$ made the GRA15 $5_{\mathrm{GT} 1}$ complemented strain. JPJS and NY conceived the study and wrote the manuscript. All authors provided comments on the paper, read and approved the final manuscript.

\section{Acknowledgements}

This work was supported by National Institutes of Health grants Al080621 to JPJS and AI081220 to MJG and GTM. NY is supported by an A*STAR NSS (PhD) graduate scholarship, WN and DL are supported by the pre-doctoral grant in the Biological Sciences (5-T32- GM007287-33). MM was supported by the Knights Templar Eye Foundation postdoctoral fellowship. The authors wish to thank David Sibley for the gift of RH-JSR strain, the MIT BioMicroCentre and Manlin Luo for help with the microarrays and members of the Saeij lab for helpful comments and technical assistance.

\section{Author details}

${ }^{1}$ Biology Department, Massachusetts Institute of Technology, 77

Massachusetts Ave, building 68-270, Cambridge, MA 02139, USA.

${ }^{2}$ Department of Biology, Boston College, 140 Commonwealth Avenue,

Chestnut Hill, Boston, MA 02467, USA.

Received: 1 March 2013 Accepted: 3 July 2013

Published: 10 July 2013

\section{References}

1. Hill D, Dubey JP: Toxoplasma gondii: transmission, diagnosis and prevention. Clin Microbiol Infect 2002, 8(10):634-640.

2. Wendte JM, Miller MA, Lambourn DM, Magargal SL, Jessup DA, Grigg ME: Self-mating in the definitive host potentiates clonal outbreaks of the apicomplexan parasites Sarcocystis neurona and Toxoplasma gondii. PLoS Genet 2010, 6(12):e1001261. 
3. Pfefferkorn ER, Pfefferkorn LC, Colby ED: Development of gametes and oocysts in cats fed cysts derived from cloned trophozoites of Toxoplasma gondii. J Parasitol 1977, 63(1):158-159.

4. Sibley LD, Ajioka JW: Population structure of Toxoplasma gondii: clonal expansion driven by infrequent recombination and selective sweeps. Annu Rev Microbiol 2008, 62:329-351.

5. Howe DK, Sibley LD: Toxoplasma gondii comprises three clonal lineages: correlation of parasite genotype with human disease. J Infect Dis 1995, 172(6):1561-1566.

6. Khan A, Dubey JP, Su C, Ajioka JW, Rosenthal BM, Sibley LD: Genetic analyses of atypical Toxoplasma gondii strains reveal a fourth clonal lineage in North America. Int J Parasitol 2011, 41(6):645-655.

7. Su C, Khan A, Zhou P, Majumdar D, Ajzenberg D, Darde ML, Zhu XQ, Ajioka JW, Rosenthal BM, Dubey JP, Sibley LD: Globally diverse Toxoplasma gondii isolates comprise six major clades originating from a small number of distinct ancestral lineages. Proc Natl Acad Sci USA 2012, 109(15):5844-5849.

8. Minot S, Melo MB, Li F, Lu D, Niedelman W, Levine SS, Saeij JP: Admixture and recombination among Toxoplasma gondii lineages explain global genome diversity. Proc Natl Acad Sci USA 2012, 109(33):13458-13463.

9. Boyle JP, Rajasekar B, Saeij JP, Ajioka JW, Berriman M, Paulsen I, Roos DS, Sibley LD, White MW, Boothroyd JC: Just one cross appears capable of dramatically altering the population biology of a eukaryotic pathogen like Toxoplasma gondii. Proc Natl Acad Sci USA 2006, 103(27):10514-10519.

10. Ajioka JW: Toxoplasma gondii: ESTs and gene discovery. Int J Parasitol 1998, 28(7):1025-1031.

11. Saeij JP, Boyle JP, Boothroyd JC: Differences among the three major strains of Toxoplasma gondii and their specific interactions with the infected host. Trends Parasitol 2005, 21(10):476-481.

12. Radke JR, Striepen B, Guerini MN, Jerome ME, Roos DS, White MW: Defining the cell cycle for the tachyzoite stage of Toxoplasma gondii. Mol Biochem Parasitol 2001, 115(2):165-175.

13. Sabin AB: Toxoplasmic encephalitis in children. J Am Med Assoc 1941 116(9):801-807.

14. Pfefferkorn ER, Pfefferkorn LC: Toxoplasma gondii: isolation and preliminary characterization of temperature-sensitive mutants. Exp Parasitol 1976, 39(3):365-376.

15. Khan A, Behnke MS, Dunay IR, White MW, Sibley LD: Phenotypic and gene expression changes among clonal type I strains of Toxoplasma gondii. Eukaryot Cell 2009, 8(12):1828-1836.

16. Sibley LD, Boothroyd JC: Virulent strains of Toxoplasma gondii comprise a single clonal lineage. Nature 1992, 359(6390):82-85.

17. Gajria B, Bahl A, Brestelli J, Dommer J, Fischer S, Gao X, Heiges M, lodice J, Kissinger JC, Mackey AJ, Pinney DF, Roos DS, Stoeckert CJ Jr, Wang H, Brunk BP: ToxoDB: an integrated Toxoplasma gondii database resource. Nucleic Acids Res 2008, 36(Database issue):D553-D556.

18. Villard O, Candolfi E, Ferguson DJ, Marcellin L, Kien T: Loss of oral infectivity of tissue cysts of Toxoplasma gondii RH strain to outbred Swiss Webster mice. Int J Parasitol 1997, 27(12):1555-1559.

19. Wiley M, Teygong C, Phelps E, Radke J, Blader IJ: Serum response factor regulates immediate early host gene expression in Toxoplasma gondiiinfected host cells. PLoS One 2011, 6(3):e18335.

20. Phelps ED, Sweeney KR, Blader IJ: Toxoplasma gondii rhoptry discharge correlates with activation of the early growth response 2 host cell transcription factor. Infect Immun 2008, 76(10):4703-4712.

21. Niedelman W, Gold DA, Rosowski EE, Sprokholt JK, Lim D, Farid Arenas A Melo MB, Spooner E, Yaffe MB, Saeij JP: The rhoptry proteins ROP18 and ROP5 mediate Toxoplasma gondii evasion of the murine, but not the human, interferon-gamma response. PLoS Pathog 2012, 8(6):e1002784.

22. Bahl A, Davis PH, Behnke M, Dzierszinski F, Jagalur M, Chen F, Shanmugam D, White MW, Kulp D, Roos DS: A novel multifunctional oligonucleotide microarray for Toxoplasma gondii. BMC Genomics 2010, 11:603.

23. Rosowski EE, Lu D, Julien L, Rodda L, Gaiser RA, Jensen KD, Saeij JP. Strain-specific activation of the NF-kappaB pathway by GRA15, a novel Toxoplasma gondii dense granule protein. J Exp Med 2011, 208(1):195-212.

24. Dunn JD, Ravindran S, Kim SK, Boothroyd JC: The Toxoplasma gondii dense granule protein GRA7 is phosphorylated upon invasion and forms an unexpected association with the rhoptry proteins ROP2 and ROP4. Infect Immun 2008, 76(12):5853-5861.
25. Jensen KD, Wang Y, Wojno ED, Shastri AJ, Hu K, Cornel L, Boedec E, Ong YC, Chien YH, Hunter CA, Boothroyd JC, Saeij JP: Toxoplasma polymorphic effectors determine macrophage polarization and intestinal inflammation. Cell Host Microbe 2011, 9(6):472-483.

26. Farrell A, Thirugnanam S, Lorestani A, Dvorin JD, Eidell KP, Ferguson DJ, Anderson-White BR, Duraisingh MT, Marth GT, Gubbels MJ: A DOC2 protein identified by mutational profiling is essential for apicomplexan parasite exocytosis. Science 2012, 335(6065):218-221.

27. Garrison E, Marth G: Haplotype-based variant detection from short-read sequencing. ArXiv e-prints 2012, 1207:3907.

28. Saeed Al, Sharov V, White J, Li J, Liang W, Bhagabati N, Braisted J, Klapa M, Currier T, Thiagarajan M, Sturn A, Snuffin M, Rezantsev A, Popov D, Ryltsov A, Kostukovich E, Borisovsky I, Liu Z, Vinsavich A, Trush V, Quackenbush J: TM4: a free, open-source system for microarray data management and analysis. Biotechniques 2003, 34(2):374-378.

29. Segal E, Friedman N, Koller D, Regev A: A module map showing conditional activity of expression modules in cancer. Nat Genet 2004, 36(10):1090-1098.

30. Subramanian A, Tamayo P, Mootha VK, Mukherjee S, Ebert BL, Gillette MA, Paulovich A, Pomeroy SL, Golub TR, Lander ES, Mesirov JP: Gene set enrichment analysis: a knowledge-based approach for interpreting genome-wide expression profiles. Proc Natl Acad Sci USA 2005, 102(43):15545-15550.

31. Gotea V, Ovcharenko I: DiRE: identifying distant regulatory elements of coexpressed genes. Nucleic Acids Res 2008, 36(Web Server issue):W133-W139.

32. Lourido S, Tang K, Sibley LD: Distinct signalling pathways control Toxoplasma egress and host-cell invasion. EMBO J 2012, 31(24):4524-4534.

33. Moon RW, Taylor CJ, Bex C, Schepers R, Goulding D, Janse CJ, Waters AP, Baker DA, Billker O: A cyclic GMP signalling module that regulates gliding motility in a malaria parasite. PLoS Pathog 2009, 5(9):e1000599.

34. Mercier C, Howe DK, Mordue D, Lingnau M, Sibley LD: Targeted disruption of the GRA2 locus in Toxoplasma gondii decreases acute virulence in mice. Infect Immun 1998, 66(9):4176-4182.

35. Mercier C, Dubremetz JF, Rauscher B, Lecordier L, Sibley LD, Cesbron-Delauw MF: Biogenesis of nanotubular network in Toxoplasma parasitophorous vacuole induced by parasite proteins. Mol Biol Cell 2002, 13(7):2397-2409.

36. Linder $\mathrm{P}$, Jankowsky E: From unwinding to clamping - the DEAD box RNA helicase family. Nat Rev Mol Cell Biol 2011, 12(8):505-516.

37. Gastens MH, Fischer HG: Toxoplasma gondii eukaryotic translation initiation factor $4 \mathrm{~A}$ associated with tachyzoite virulence is downregulated in the bradyzoite stage. Int J Parasitol 2002, 32(10):1225-1234.

38. Wasmuth JD, Pszenny V, Haile S, Jansen EM, Gast AT, Sher A, Boyle JP, Boulanger MJ, Parkinson J, Grigg ME: Integrated bioinformatic and targeted deletion analyses of the SRS gene superfamily identify SRS29C as a negative regulator of Toxoplasma virulence. MBio 2012, 3(6): e00321-12.

39. Frenal K, Polonais V, Marq JB, Stratmann R, Limenitakis J, Soldati-Favre D: Functional dissection of the apicomplexan glideosome molecular architecture. Cell Host Microbe 2010, 8(4):343-357.

40. Gaskins E, Gilk S, DeVore N, Mann T, Ward G, Beckers C: Identification of the membrane receptor of a class XIV myosin in Toxoplasma gondii. J Cell Biol 2004, 165(3):383-393.

41. Fauquenoy S, Hovasse A, Sloves PJ, Morelle W, Dilezitoko Alayi T, Slomianny C, Werkmeister E, Schaeffer C, Van Dorsselaer A, Tomavo S: Unusual $\mathrm{N}$-glycan structures required for trafficking Toxoplasma gondii GAP50 to the inner membrane complex regulate host cell entry through parasite motility. Mol Cell Proteomics 2011, 10(9):M111.008953.

42. Bradley PJ, Ward C, Cheng SJ, Alexander DL, Coller S, Coombs GH, Dunn JD, Ferguson DJ, Sanderson SJ, Wastling JM, Boothroyd JC: Proteomic analysis of rhoptry organelles reveals many novel constituents for host-parasite interactions in Toxoplasma gondii. J Biol Chem 2005, 280(40):34245-34258.

43. Alexander DL, Mital J, Ward GE, Bradley P, Boothroyd JC: Identification of the moving junction complex of Toxoplasma gondii: a collaboration between distinct secretory organelles. PLoS Pathog 2005, 1(2):e17.

44. Lescault PJ, Thompson AB, Patil V, Lirussi D, Burton A, Margarit J, Bond J, Matrajt M: Genomic data reveal Toxoplasma gondii differentiation mutants are also impaired with respect to switching into a novel extracellular tachyzoite state. PLoS One 2010, 5(12):e14463.

45. Simon I, Barnett J, Hannett N, Harbison CT, Rinaldi NJ, Volkert TL, Wyrick J, Zeitlinger J, Gifford DK, Jaakkola TS, Young RA: Serial regulation of transcriptional regulators in the yeast cell cycle. Cell 2001, 106(6):697-708. 
46. Buchholz KR, Fritz HM, Chen X, Durbin-Johnson B, Rocke DM, Ferguson DJ, Conrad PA, Boothroyd JC: Identification of tissue cyst wall components by transcriptome analysis of in vivo and in vitro Toxoplasma gondii bradyzoites. Eukaryot Cell 2011, 10(12):1637-1647.

47. Craver MP, Rooney PJ, Knoll L: Isolation of Toxoplasma gondii development mutants identifies a potential proteophosphogylcan that enhances cyst wall formation. Mol Biochem Parasitol 2010, 169(2):120-123.

48. Coppin A, Dzierszinski F, Legrand S, Mortuaire M, Ferguson D, Tomavo S: Developmentally regulated biosynthesis of carbohydrate and storage polysaccharide during differentiation and tissue cyst formation in Toxoplasma gondii. Biochimie 2003, 85(3-4):353-361

49. Virreira Winter S, Niedelman W, Jensen KD, Rosowski EE, Julien L, Spooner E, Caradonna K, Burleigh BA, Saeij JP, Ploegh HL, Frickel EM: Determinants of GBP recruitment to Toxoplasma gondii vacuoles and the parasitic factors that control it. PLoS One 2011, 6(9):e24434.

50. Collazo CM, Yap GS, Sempowski GD, Lusby KC, Tessarollo L, Woude GF, Sher A, Taylor GA: Inactivation of LRG-47 and IRG-47 reveals a family of interferon gamma-inducible genes with essential, pathogen-specific roles in resistance to infection. J Exp Med 2001, 194(2):181-188.

51. Cheung VG, Nayak RR, Wang IX, Elwyn S, Cousins SM, Morley M, Spielman RS: Polymorphic cis- and trans-regulation of human gene expression. PLOS Biol 2010, 8(9):e1000480.

52. Behnke MS, Wootton JC, Lehmann MM, Radke JB, Lucas O, Nawas J, Sibley LD, White MW: Coordinated progression through two subtranscriptomes underlies the tachyzoite cycle of Toxoplasma gondii. PLoS One 2010, 5(8):e12354.

53. Miller JE, Reese JC: Ccr4-Not complex: the control freak of eukaryotic cells. Crit Rev Biochem Mol Biol 2012, 47(4):315-333.

54. Schoneck R, Billaut-Mulot O, Numrich P, Ouaissi MA, Krauth-Siegel RL: Cloning, sequencing and functional expression of dihydrolipoamide dehydrogenase from the human pathogen Trypanosoma cruzi. Eur J Biochem 1997, 243(3):739-747.

55. Venugopal A, Bryk R, Shi S, Rhee K, Rath P, Schnappinger D, Ehrt S, Nathan C: Virulence of Mycobacterium tuberculosis depends on lipoamide dehydrogenase, a member of three multienzyme complexes. Cell Host Microbe 2011, 9(1):21-31.

56. Ehrenman K, Sehgal A, Lige B, Stedman TT, Joiner KA, Coppens I: Novel roles for ATP-binding cassette $\mathrm{G}$ transporters in lipid redistribution in Toxoplasma. Mol Microbiol 2010, 76(5):1232-1249.

57. Saksouk N, Bhatti MM, Kieffer S, Smith AT, Musset K, Garin J, Sullivan WJ Jr, Cesbron-Delauw MF, Hakimi MA: Histone-modifying complexes regulate gene expression pertinent to the differentiation of the protozoan parasite Toxoplasma gondii. Mol Cell Biol 2005, 25(23):10301-10314.

58. Dixon SE, Stilger KL, Elias EV, Naguleswaran A, Sullivan WJ Jr: A decade of epigenetic research in Toxoplasma gondii. Mol Biochem Parasitol 2010, 173(1):1-9.

59. Li J, Mahajan A, Tsai MD: Ankyrin repeat: a unique motif mediating protein-protein interactions. Biochemistry 2006, 45(51):15168-15178.

60. Al-Khodor S, Price CT, Kalia A, Abu Kwaik Y: Functional diversity of ankyrin repeats in microbial proteins. Trends Microbiol 2010, 18(3):132-139.

61. Friesen J, Fleige T, Gross U, Bohne W: Identification of novel bradyzoitespecific Toxoplasma gondii genes with domains for protein-protein interactions by suppression subtractive hybridization. Mol Biochem Parasitol 2008, 157(2):228-232.

62. Michelin A, Bittame A, Bordat Y, Travier L, Mercier C, Dubremetz JF, Lebrun M: GRA12, a Toxoplasma dense granule protein associated with the intravacuolar membranous nanotubular network. Int J Parasitol 2009 39(3):299-306

63. Peixoto L, Chen F, Harb OS, Davis PH, Beiting DP, Brownback CS, Ouloguem D, Roos DS: Integrative genomic approaches highlight a family of parasitespecific kinases that regulate host responses. Cell Host Microbe 2010, 8(2):208-218

64. Melo MB, Jensen KD, Saeij JP: Toxoplasma gondii effectors are master regulators of the inflammatory response. Trends Parasitol 2011 27(11):487-495.

65. Hunter S, Apweiler R, Attwood TK, Bairoch A, Bateman A, Binns D, Bork P, Das U, Daugherty L, Duquenne L, Finn RD, Gough J, Haft D, Hulo N, Kahn D, Kelly E, Laugraud A, Letunic I, Lonsdale D, Lopez R, Madera M, Maslen J, McAnulla C, McDowall J, Mistry J, Mitchell A, Mulder N, Natale D, Orengo C, Quinn AF, et al: InterPro: the integrative protein signature database. Nucleic Acids Res 2009, 37(Database issue):D211-5.
66. Hayden MS, Ghosh S: Shared principles in NF-kappaB signaling. Cell 2008, 132(3):344-362.

67. Robben PM, Mordue DG, Truscott SM, Takeda K, Akira S, Sibley LD: Production of IL-12 by macrophages infected with Toxoplasma gondii depends on the parasite genotype. J Immunol 2004, 172(6):3686-3694.

68. Sanjabi S, Hoffmann A, Liou HC, Baltimore D, Smale ST: Selective requirement for c-Rel during IL-12 P40 gene induction in macrophages. Proc Natl Acad Sci USA 2000, 97(23):12705-12710.

69. Molestina RE, Payne TM, Coppens I, Sinai AP: Activation of NF-kappaB by Toxoplasma gondii correlates with increased expression of antiapoptotic genes and localization of phosphorylated lkappaB to the parasitophorous vacuole membrane. J Cell Sci 2003, 116(Pt 21):4359-4371.

70. Molestina RE, Sinai AP: Host and parasite-derived IKK activities direct distinct temporal phases of NF-kappaB activation and target gene expression following Toxoplasma gondii infection. J Cell Sci 2005, 118(Pt 24):5785-5796.

71. Rome ME, Beck JR, Turetzky JM, Webster P, Bradley PJ: Intervacuolar transport and unique topology of GRA14, a novel dense granule protein in Toxoplasma gondii. Infect Immun 2008, 76(11):4865-4875.

72. Coppens I, Dunn JD, Romano JD, Pypaert M, Zhang H, Boothroyd JC, Joiner KA: Toxoplasma gondii sequesters lysosomes from mammalian hosts in the vacuolar space. Cell 2006, 125(2):261-274.

73. Travier L, Mondragon R, Dubremetz JF, Musset K, Mondragon M, Gonzalez S, Cesbron-Delauw MF, Mercier C: Functional domains of the Toxoplasma GRA2 protein in the formation of the membranous nanotubular network of the parasitophorous vacuole. Int J Parasitol 2008, 38(7):757-773.

74. Braun L, Travier L, Kieffer S, Musset K, Garin J, Mercier C, Cesbron-Delauw MF: Purification of Toxoplasma dense granule proteins reveals that they are in complexes throughout the secretory pathway. Mol Biochem Parasitol 2008, 157(1):13-21.

doi:10.1186/1471-2164-14-467

Cite this article as: Yang et al:: Genetic basis for phenotypic differences between different Toxoplasma gondii type I strains. BMC Genomics 2013 14:467.

\section{Submit your next manuscript to BioMed Central and take full advantage of:}

- Convenient online submission

- Thorough peer review

- No space constraints or color figure charges

- Immediate publication on acceptance

- Inclusion in PubMed, CAS, Scopus and Google Scholar

- Research which is freely available for redistribution 